\title{
Deficient Surveillance and Phagocytic Activity of Myeloid Cells Within Demyelinated Lesions in Aging Mice Visualized by Ex Vivo Live Multiphoton Imaging
}

\author{
Khalil S. Rawji, Janson Kappen, Weiwen Tang, Wulin Teo, Jason R. Plemel, Peter K. Stys, and V. Wee Yong \\ Hotchkiss Brain Institute and the Department of Clinical Neurosciences, University of Calgary, Calgary, Alberta T2N 4N1, Canada
}

\begin{abstract}
Aging impairs regenerative processes including remyelination, the synthesis of a new myelin sheath. Microglia and other infiltrating myeloid cells such as macrophages are essential for remyelination through mechanisms that include the clearance of inhibitory molecules within the lesion. Prior studies have shown that the quantity of myeloid cells and the clearance of inhibitory myelin debris are deficient in aging, contributing to the decline in remyelination efficiency with senescence. It is unknown, however, whether the impaired clearance of debris is simply the result of the reduced number of phagocytes or if the dynamic activity of myeloid cells within the demyelinating plaque also declines with aging and this question is relevant to the proper design of therapeutics to mobilize myeloid cells for repair. Herein, we describe a high-resolution multiphoton ex vivo live imaging protocol that visualizes individual myelinated/demyelinated axons and lipid-containing myeloid cells to investigate the demyelinated lesion of aging female mice. We found that aging lesions have fewer myeloid cells and that these have reduced phagocytosis of myelin. Although the myeloid cells are actively migratory within the lesion of young mice and have protrusions that seem to survey the environment, this motility and surveillance is significantly reduced in aging mice. Our results emphasize the necessity of not only increasing the number of phagocytes, but also enhancing their activity once they are within demyelinated lesions. The high-resolution live imaging of demyelinated lesions can serve as a platform with which to discover pharmacological agents that rejuvenate intralesional remodeling that promotes the repair of plaques.
\end{abstract}

Key words: demyelination; live imaging; macrophages; microglia

Significance Statement

The repair of myelin after injury depends on myeloid cells that clear debris and release growth factors. As organisms age, remyelination becomes less efficient correspondent with fewer myeloid cells that populate the lesions. It is unknown whether the dynamic activity of cells within lesions is also altered with age. Herein, using high-resolution multiphoton ex vivo live imaging with several novel features, we report that myeloid cells within demyelinated lesions of aging mice have reduced motility, surveillance, and phagocytic activity, suggesting an intralesional impairment that may contribute to the age-related decline in remyelination efficiency. Medications to stimulate deficient aging myeloid cells should not only increase their representation, but also enter into lesions to stimulate their activity.

\section{Introduction}

Demyelination is the loss of the myelin sheath surrounding an axon, resulting in impaired axonal conduction and degeneration

Received Aug. 18, 2017; revised Dec. 22, 2017; accepted Jan. 12, 2018.

Author contributions: K.S.R., J.K., W. Tang, W. Teo, J.R.P., P.K.S., and V.W.Y. designed research; K.S.R., J.K., W. Tang, W. Teo, and J.R.P. performed research; K.S.R., J.K., W. Tang, W. Teo, J.R.P., P.K.S., and V.W.Y. analyzed data; K.S.R., J.K., W. Tang, W. Teo, J.R.P., P.K.S., and V.W.Y. wrote the paper.

This work was supported by operating grants from the Canadian Institutes of Health Research (CIHR), the Multiple Sclerosis Scientific Research Foundation, the Multiple Sclerosis Society of Canada, and the Alberta InnovatesHealth Solutions (AIHS) CRIO Team program. K.S.R. is supported by a Vanier Canada Graduate Scholarship and a studentship from the University of Calgary Faculty of Medicine. W.Tang was supported by a summer studentship from Alberta Innovates Health Solutions. J.R.P was supported by fellowships from CIHR, T. Chen Fong, AIHS, and the Donna Joan 0xford award from the MS Society of Canada. We thank the Hotchkiss Brain Institute Advanced
(Irvine and Blakemore, 2008; Matute and Ransom, 2012). Remyelination is the synthesis of a new myelin sheath and is important for restoring efficient saltatory conduction and metabolic support to the axon (Franklin and Kotter, 2008; Saab et al., 2013), reflecting an endogenous process involving the recruitment and differentiation of oligodendrocyte precursor cells (OPCs) into

Microscopy Platform (AMP) Facility for use of the Nikon A1R multiphoton microscope and NIS Elements and the Live Cell Imaging Facility for access to Imaris software.

The authors declare no competing financial interests.

Correspondence should be addressed to Dr. V. Wee Yong, University of Calgary, 3330 Hospital Drive, Calgary, Alberta T2N 4N1, Canada. E-mail: vyong@ucalgary.ca.

D0I:10.1523/JNEUROSCI.2341-17.2018

Copyright $\odot 2018$ the authors $\quad 0270-6474 / 18 / 381973-16 \$ 15.00 / 0$ 
myelinating oligodendrocytes (Franklin and ffrench-Constant, 2008). Many factors influence the remyelination response, including inhibitors in the microenvironment, inflammation, and the age of the subject (Kotter et al., 2011).

Focal models of demyelination have shown that the innate immune response, consisting of myeloid cells such as activated microglia and infiltrating monocyte-derived macrophages, is essential for remyelination (Kotter et al., 2001, 2005). These innate immune cells release important growth factors for OPC maturation in addition to clearing inhibitory myelin debris (Kotter et al., 2005; Miron et al., 2013; Yuen et al., 2013). This inflammatory response declines with aging (Shaw et al., 2013; Rawji et al., $2016 \mathrm{~b}$ ) and is thought to underlie the deficiency in remyelination that occurs with senescence (Zhao et al., 2006; Ruckh et al., 2012). The decreased inflammatory response in aging is manifested as delayed and lowered macrophage/microglia recruitment, a dysregulation in several chemokines and cytokines, and an accumulation of myelin debris (Zhao et al., 2006; Ruckh et al., 2012).

Studies conducted to date have used static histological sections to document the reduced representation of macrophages/ microglia within focally demyelinated lesions from aging animals. Therefore, it is not clear whether these cells, once within the lesion, are dynamically altered in their activity in surveying the lesion microenvironment. This has implications for therapeutics because strategies to enhance the representation of myeloid cells into aging demyelinated lesions may be ineffectual if the infiltrating cells remain compromised within the lesion microenvironment. We therefore sought to visualize the activity of microglia and infiltrating myeloid cells within demyelinated lesions and investigate whether aging cells are deficient in their dynamic activity. Using multiphoton ex vivo live imaging, we find that aging myeloid cells are significantly less motile and display reduced surveillance in the lesion microenvironment. In addition, aging lesions have fewer myeloid cells, many of which are deficient in myelin phagocytosis. These observations provide insights into the factors influencing the decreased efficiency of remyelination in the aging demyelinated lesion and introduce a novel high-resolution technique for imaging the lesion in real time.

\section{Materials and Methods}

Mice. All experiments were performed in accordance with the Animal Care Committee at the University of Calgary. Mice were housed at the University of Calgary Animal Resource Center per regulations stated in the Canadian Council of Animal Care. For live imaging experiments, heterozygous Cx3 $\mathrm{crl} 1^{\mathrm{GFP} /+}$ mice (RRID:IMSR_JAX:005582) (Jung et al., 2000), which are used to visualize microglia and other myeloid cells such as macrophages and dendritic cells, were crossed with Thy1 $\mathrm{YFP}^{+}$mice (RRID:IMSR_JAX:003782) (Feng et al., 2000), which are used to visualize dorsal column axons, to produce double-transgenic mice capable of visualizing both axons and myeloid cells concurrently (Stirling et al., 2014). For histology and immunofluorescence, homozygous $C c r 2^{\text {RFP/RFP }}$ : $\mathrm{C} \times 3 \mathrm{cr} 1^{\mathrm{GFP} / \mathrm{GFP}}$ mice (obtained from Dr. Paul Kubes, University of Calgary) were crossed with C57BL/6 mice (purchased from Charles River Laboratories) to generate $C c r 2^{\mathrm{RFP} /+}: C x 3 c r 1^{\mathrm{GFP} /+}$ mice (Saederup et al., 2010). All mice were on a C57BL/6 background. Female mice were used in this study at 2-3 months of age (young) and 9-12 months of age (aging).

Lysolecithin demyelination. Mice were anesthetized with ketamine (100 $\mathrm{mg} / \mathrm{kg}$ ) and xylazine $(10 \mathrm{mg} / \mathrm{kg})$ administered through intraperitoneal injection. The analgesic buprenorphine $(0.05 \mathrm{mg} / \mathrm{kg})$ was administered subcutaneously. Ophthalmic solution was applied to each eye to keep the eyes moist during surgery. The back was shaved with a razor and the surgical field was disinfected with $70 \%$ ethanol and iodine. Focal demyelination was produced by intraspinal injection of the lipid-disrupting detergent lysolecithin (L1381, lysophosphatidylcholine; Sigma-Aldrich) using a pulled microcapillary (TW150F-3; World Precision Instruments) attached to a $10 \mu \mathrm{l}$ syringe ( $\# 701$; Hamilton) with polyethylene tubing (427406; Intramedic). In preparation of intraspinal injection, the microcapillary was filled with $0.5 \mu \mathrm{l}$ of $1 \%$ lysolecithin in PBS.

The sedated mouse was positioned in a stereotactic frame and a midline incision was performed over the upper back. Retractors were used to separate the underlying adipose and muscle tissue to reveal the vertebral column. The protrusion of the T2 thoracic vertebra was used to locate the intervertebral space between $\mathrm{T} 3$ and T4, where tissue was removed with spring scissors, exposing the dorsal spinal cord. A 30 gauge metal needle was used to clear the dura, after which the midline dorsal column white matter was distinguished from the gray matter. Using the stereotaxic frame, the microcapillary was lowered $100 \mu \mathrm{m}$ below the pial surface into the dorsal white matter, after which $0.5 \mu \mathrm{l}$ of lysolecithin was injected at a rate of $0.25 \mu \mathrm{l} / \mathrm{min}$. After injection, the microcapillary was maintained in position for an additional $2 \mathrm{~min}$ to prevent backflow of lysolecithin. The microcapillary was then removed, the muscle and skin were sutured, and the mouse was placed in a thermally controlled environment to recover. A second dose of buprenorphine $(0.05 \mathrm{mg} / \mathrm{kg})$ was administered subcutaneously $12-16 \mathrm{~h}$ after surgery.

Ex vivo multiphoton live imaging. Three days after lysolecithininduced demyelination, mice were killed and transcardially perfused with $20 \mathrm{ml}$ of equilibrated cold artificial CSF (aCSF). The aCSF solution was prepared per the following concentrations: $151 \mathrm{~mm} \mathrm{NaCl}, 3 \mathrm{~mm} \mathrm{KCl}$, $2 \mathrm{mM} \mathrm{CaCl}_{2}, 1.25 \mathrm{~mm} \mathrm{NaH}_{2} \mathrm{PO}_{4}, 2 \mathrm{~mm} \mathrm{MgSO}_{4}, 26 \mathrm{~mm} \mathrm{NaHCO}_{3}$, and 10 $\mathrm{mm}$ dextrose. Laminectomy of the dorsal vertebral column was performed to expose the spinal cord. A $1 \mathrm{~cm}$ segment of the thoracic spinal cord encompassing T3/T4 was excised, leaving the ventral vertebral column intact. The ventral vertebral column of the spinal cord segment was then used to suspend the sample in an imaging chamber (RC-27L; Harvard Apparatus), eliminating contact with the axons. The suspended spinal cord was then incubated for $10 \mathrm{~min}$ with the lipophilic dye Nile red (N-1142; Life Technologies) at a final concentration of $10 \mu \mathrm{M}$ to visualize myelin.

A perfusion system was used to keep the spinal cord segment viable by continuously circulating aCSF within the imaging chamber. The aCSF was bubbled with $95 \% \mathrm{O}_{2} / 5 \% \mathrm{CO}_{2}$ and maintained at a constant temperature of $35^{\circ} \mathrm{C}$ using an in-line thermal sensor (64-0353; Harvard Apparatus) and an objective heater system (CL-100; Warner Instruments). Once the spinal cord was suspended in the imaging chamber, we allowed $1 \mathrm{~h}$ to elapse to ensure the viability of the spinal cord sample. If $>3 \%$ of axons displayed features of axonal dystrophy, the sample was discarded. We have shown previously that the ex vivo spinal cord can be maintained in a viable state for up to $12 \mathrm{~h}$ using this perfusion system (Stirling et al., 2014).

All images were acquired using a Nikon A1R multiphoton microscope using a $25 \times$ water-immersion apochromatic lens with a 1.1 numerical aperture. Samples were excited with a wavelength of $930 \mathrm{~nm}$ (GFP, YFP, and Nile red) at $\sim 10-15 \mathrm{~mW}$ at the tissue. A spectral detector was used to collect emission spectra ranging from $490-650 \mathrm{~nm}$ at $10 \mathrm{~nm}$ intervals, allowing the GFP, YFP, and Nile red emission spectra to be captured. All images were acquired at the center of the lesion with dimensions of 200 $\mu \mathrm{m}$ by $200 \mu \mathrm{m}$. $Z$-stacks with an optical thickness of $\approx 1.5 \mu \mathrm{m}$ per slice were taken to obtain a depth of $\sim 30 \mu \mathrm{m}$. Images were taken in the same location every $15 \mathrm{~min}$ over the course of $2-3 \mathrm{~h}$ to examine the dynamics of the lesion site. Due to the extent of imaging in the same location, a minor degree of photobleaching may be present. Control experiments of uninjured dorsal columns from young and aging mice were also imaged using the same protocol as the lesioned dorsal columns.

Postacquisition image analysis. For visualization and analysis, the 4D image data were imported into ImageTrak (written by P.K.S.). Image stacks were autoregistered to correct for $X-Y$ drift between each image. The images were spectrally unmixed as we described previously (Stirling et al., 2014). Spectral unmixing was necessary to separate overlapping emission spectra such as GFP and YFP. Emission maxima separated by $10 \mathrm{~nm}$ can be separated and pseudocolored for visualization, producing a tricolor image in which red represents Nile red, green represents GFP, and white represents YFP. To generate accurate spectral unmixing results, regions of interest are selected in which pure YFP, GFP, and Nile 
A

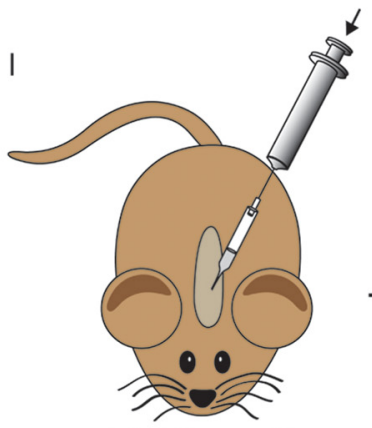

Inject Mouse with $0.5 \mu \mathrm{L} 1 \%$ Lysolecithin

VI

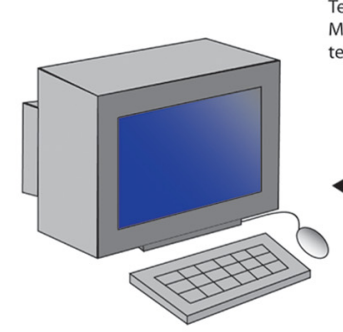

Post-acquisition Analysis
II

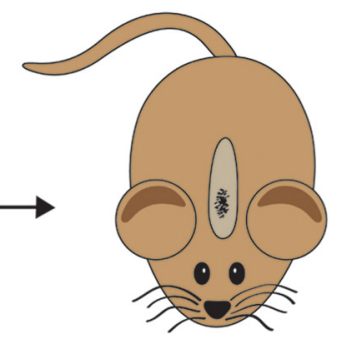

Euthanize Mouse

3 Days Post-Injury

V

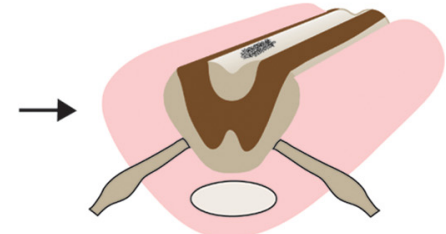

Isolate Thoracic Spinal Cord from Mouse

IV

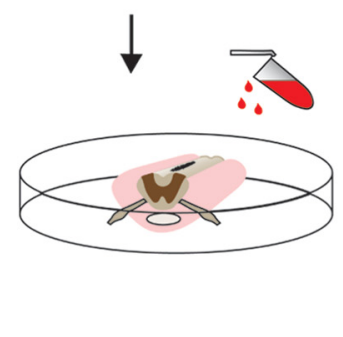

Incubate Spinal Cord in aCSF and Nile Red

\section{B}
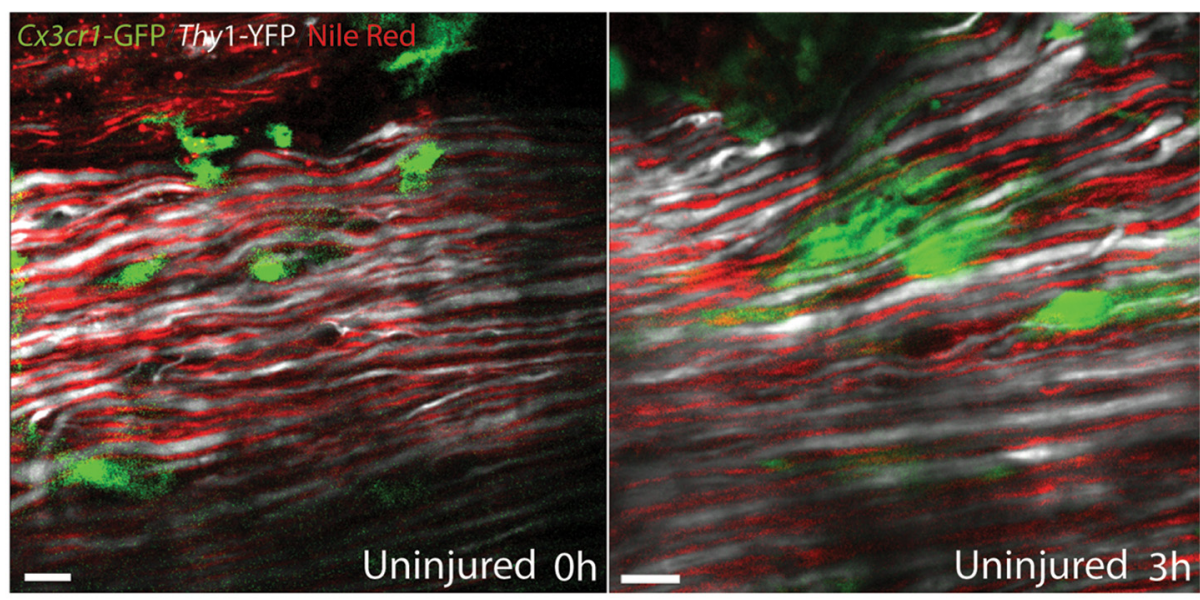

C

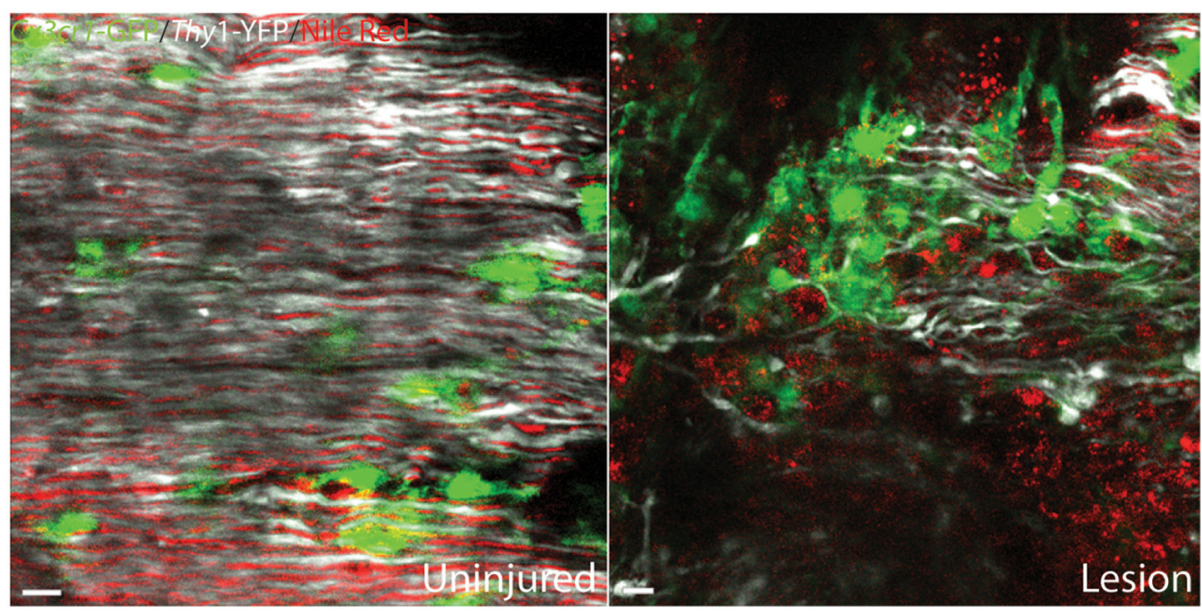

Figure 1. Ex vivo multiphoton live imaging of a demyelinated dorsal column in $C \times 3 \mathrm{Cr} 1^{\mathrm{GFP} /+}$ :Thy $1 \mathrm{YFP}{ }^{+}$mice. $A$, Schematic of ex vivo live imaging protocol depicting injection of lysolecithin into the dorsal spinal cord with a pulled microcapillary, followed by excision of the spinal cord at $3 \mathrm{~d}$ after demyelination, incubation with Nile red, suspension and immersion of spinal cord in aCSF perfusion system, imaging under multiphoton microscope, and post-acquisition analysis. B, Representative spectrally unmixed images acquired from (Figure legend continues.) 
red is present. The spectral signatures from these regions of interest are then used to unmix the remainder of the images. Within each image, $z$-stacks at the top and the bottom of each image volume were compressed to produce a maximum intensity projection (MIP). The spectrally unmixed MIPs at each time point were merged together to produce a $2 \mathrm{D}$ video of lesion activity over $2-3 \mathrm{~h}$.

Using the videos, the number of phagocytic $\mathrm{C} \times 3 \mathrm{cr} 1^{\mathrm{GFP} /+}$ cells were quantified at each time point. Phagocytic cells were defined as $\mathrm{C} \times 3 \mathrm{crl} 1^{\mathrm{GFP} /+}$ cells that contained visible Nile red particles within the soma. The number of phagocytic $C \times 3 c r 1^{\mathrm{GFP} /+}$ cells at each time point was then averaged to produce an estimate of the number of $\mathrm{Cx} 3 \mathrm{crl} 1^{\mathrm{GFP} /+}$ cells within the lesion.

To investigate $3 \mathrm{D}$ aspects such as morphology and motility of lesional $\mathrm{C} \times 3 \mathrm{cr} 1^{\mathrm{GFP} /+}$ cells, image stacks acquired from the multiphoton microscope were spectrally unmixed in NIS Elements (Nikon; RRID:SCR_014329). For this spectral unmixing sequence, the preloaded spectral signatures for "EGFP" and "EYFP" were used. To unmix Nile red, the spectral signature for "Alexa Fluor 594" was selected. The unmixed image stacks were then imported into Imaris (Bitplane; RRID:SCR_007370), in which 3D reconstructions were produced from the $z$-stacks. Surfaces were created using the same parameters for both young and aging lesions. Surfaces were subsequently edited after creation. Reconstructed images at different time points were then merged to create a single 3D volumetric rendering of the lesion over 2-3 h. ImarisTrack was used to track the distance, displacement, and speed of individual $\mathrm{C} \times 3 \mathrm{crl} 1^{\mathrm{GFP} /+}$ cells over time. A reference frame was applied to an obvious feature such as an axonal endbulb in each frame to correct for translational $X-Y-Z$ drift over time. Our best effort was used to correct for rotational drift. All motility measurements were made in relation to the reference frame. Volumetric rendering was used to obtain measurements such as cell surface area, volume, and sphericity. In addition, ImarisColoc was used to quantify the percentage of Nile red-labeled lipids present within Cx3cr $1^{\mathrm{GFP} /+}$ cells.

Histology and immunofluorescence. To characterize the Cx3cr1 $1^{\mathrm{GFP} /+}$ cells in the lesion, $C c r 2^{\mathrm{RFP} /+}: \mathrm{Cx} 3 \mathrm{cr} 1^{\mathrm{GFP} /+}$ mice (Saederup et al., 2010) were injected with $0.5 \mu \mathrm{l}$ of $1.0 \%$ lysolecithin into the dorsal white matter and then euthanized $3 \mathrm{~d}$ after demyelination. Mice were killed by transcardial perfusion of $20 \mathrm{ml}$ of cold PBS followed by cold 4\% phosphatebuffered paraformaldehyde (PFA). The spinal cord was dissected and a 1 $\mathrm{cm}$ segment of the thoracic spinal cord encompassing the lesion was isolated. This segment was postfixed in $4 \%$ PFA overnight at $4^{\circ} \mathrm{C}$, followed by cryoprotection in $30 \%$ sucrose for 3 nights at $4^{\circ} \mathrm{C}$. The spinal cord segments were then frozen in cryomolds containing optimal cutting temperature medium (25608-930, VWR) using 2-methylbutane (M32631; Sigma-Aldrich) and dry ice and then stored at $-80^{\circ} \mathrm{C}$ until sectioning. A cryostat was used to obtain coronal sections at a thickness of $20 \mu \mathrm{m}$, after which sections were stained for histology and immunofluorescence.

To visualize myelin, sections were stained with eriochrome cyanine $\mathrm{R}$ (32752; Sigma-Aldrich) and neutral red. Sections were first thawed at room temperature for $30 \mathrm{~min}$, followed by transfer to CitriSolv (22-143975; Fisher Scientific) for $1 \mathrm{~min}$. Slides were then rehydrated in graded ethanol solutions (isopropanol, 100\%, 95\%, 90\%, 70\%, 50\%, and water) for $1 \mathrm{~min}$ each. Slides were incubated in eriochrome cyanine solution for $15 \mathrm{~min}$. The slides were then washed for $1 \mathrm{~min}$ in water and differentiated with $0.5 \%$ ammonium hydroxide (320145; Sigma-Aldrich) for $10 \mathrm{~s}$. Slides were washed with water for $1 \mathrm{~min}$ and then dehydrated in graded ethanol solutions (water, 50\%, 70\%, 90\%, 95\%, 100\%, and isopropanol)

$\leftarrow$

(Figure legend continued.) $\mathrm{C}_{3} 3 \mathrm{Cr} \mathrm{G}^{\mathrm{GFP} /+}$ :Thy $7 \mathrm{YFP}^{+}$uninjured mice incubated with Nile red. CX3 $\mathrm{Cr} 7^{\mathrm{GFP} /+}$ microglia (green) are distributed throughout the spinal cord. Thy $7 \mathrm{YFP}^{+}$dorsal column axons are pseudocolored in white and run longitudinally and in parallel. Myelin is in red and appears as intact myelin sheaths surrounding Thy $7 \mathrm{YFP}^{+}{ }^{+}$axons. The health and viability of the spinal cord preparation can be sustained for $3 \mathrm{~h}$, as evidenced by the lack of axonal spheroids or other dystrophic features. C, Representative spectrally unmixed images contrasting an uninjured dorsal column with a lesioned dorsal column $3 \mathrm{~d}$ after demyelination. In the latter, axons are disrupted or transected and myelin is no longer present as continuous structures around axons. Scale bars, $10 \mu \mathrm{m}$. for $1 \mathrm{~min}$ each. Slides were finally stored in CitriSolv and coverslipped with Acrytol mounting medium (3801700; Leica Biosystems). Brightfield images were captured using an Olympus BX51 microscope.

For immunofluorescence analysis, frozen slides were thawed at room temperature for $30 \mathrm{~min}$. Slides were first blocked with a PBS solution containing $10 \%$ horse serum, $1 \%$ bovine serum albumin, $0.1 \%$ cold fish gelatin, $0.1 \%$ Triton X-100, and $0.05 \%$ Tween 20 . Sections were then incubated with primary antibodies overnight in a PBS solution containing $1 \%$ bovine serum albumin, $0.1 \%$ cold fish gelatin, and $0.5 \%$ Triton $\mathrm{X}-100$. To amplify the signal produced from the $C x 3 \mathrm{crl} 1^{\mathrm{GFP} /+}$ cells, a chicken polyclonal anti-GFP antibody (Aves Labs, GFP-1020; 1:1000; RRID:AB_10000240) was used. To stain for macrophages/microglia, a rabbit polyclonal anti-Ibal antibody (Wako, 019-19741; 1:500; RRID: AB_839504) was used. To assess myeloid cell activation markers, a rat monoclonal anti-CD16/CD32 antibody (BD PharMingen, 553142; 1:100; RRID:AB_394657) and a rat monoclonal anti-MHC II antibody (Bio-Rad, MCA1387; 1:100; RRID:AB_321620) were used. An Armenian hamster monoclonal anti-CD11c antibody (Abcam, ab33483; 1:100; RRID:AB_726084) was used to stain dendritic cells. After 35 min washes with PBS containing $0.05 \%$ Tween 20 , corresponding secondary antibodies $(1: 400)$ were added with nuclear yellow $(1: 1000)$ for $2 \mathrm{~h}$ at room temperature. Sections were washed again 3 times for 5 min each in PBS containing $0.05 \%$ Tween 20 , after which they were coverslipped with Gelvatol mounting medium. Images were captured on a Nikon C1si spectral confocal microscope. Brightness and contrast was adjusted using ImageJ (RRID:SCR_003070). To assess the percentage of C $\times 3$ cr $1^{\mathrm{GFP} /+}$ cells expressing either CD16/CD32 or MHC II, ImarisColoc was used.

Experimental design and statistical analyses. Statistical analysis and production of graphs was performed using GraphPad Prism 6.0 software (RRID:SCR_015807). For all analyses, three to four mice per group were analyzed. For cell density measurements, each mouse was considered an $n$ of 1 . For morphology measurements in young and aging uninjured controls, between 1 and 11 cells were quantified per mouse from 3 young mice and 3 aging mice. For morphology and motility measurements in demyelinated lesions, each cell was considered an $n$ of 1 and between 41 and 145 cells were quantified per mouse across 3-4 mice per group. For analysis of the percentage of phagocytosis, the colocalization of Nile red at each time point was considered an $n$ of 1 and 7 time points were assessed per mouse across 3-4 mice. All analyses consisting of two groups were conducted with one-tailed Student's $t$ tests. All analyses consisting of four groups with two independent variables (time and age) were conducted with a two-way ANOVA with a Bonferroni's multiplecomparisons test. Graphs in the figures display the mean and SEM.

\section{Results}

\section{Live multiphoton imaging of demyelinated dorsal column lesions}

To produce a focal demyelinating lesion in the dorsal column with minimal mechanical damage, we injected lysolecithin via microcapillary attached to a $10 \mu$ l syringe (Fig. $1 A$ ). We performed ex vivo live imaging experiments on naive and lesioned dorsal column tissue $3 \mathrm{~d}$ after demyelination. To visualize microglia, infiltrating myeloid cells, and axons, we performed all our experiments on $\mathrm{C} \times 3 \mathrm{cr} 1^{\mathrm{GFP} /+}:$ Thy $1 \mathrm{YFP}^{+}$mice in which the myeloid cells express GFP under control of the fractalkine receptor (CX3CR1) promoter and axons express YFP under the control of the neuronal Thyl promoter (Feng et al., 2000; Jung et al., 2000; Stirling et al., 2014). We used the lipophilic dye Nile red to label myelin (Arnaud et al., 2009; Stirling et al., 2014). We acquired high-resolution images under the multiphoton microscope, which we then analyzed using various software programs (Fig. 1A).

Imaging of the healthy dorsal column revealed longitudinal Thy $1 \mathrm{YFP}^{+}$axons ensheathed by Nile red-positive myelin sheaths (Fig. 1B). Ramified C $\times 3 c r 1^{\mathrm{GFP} /+}$ microglia were evenly distributed in the spinal cord. We were able to maintain axonal and myelin viability for at least $3 \mathrm{~h}$ of imaging, as reflected by a lack 
A

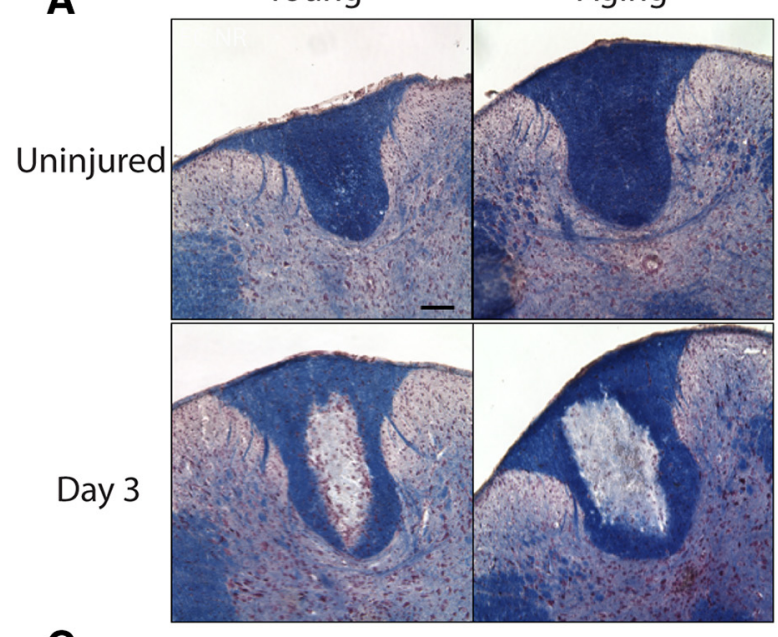

B

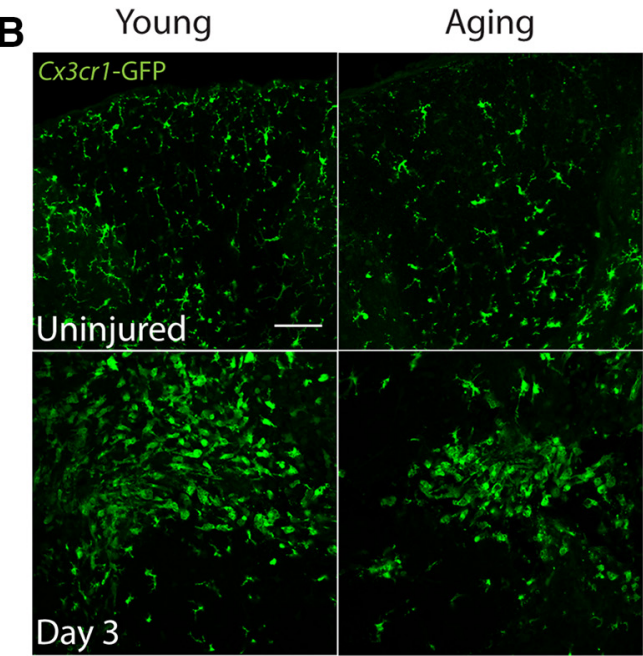

Day 3

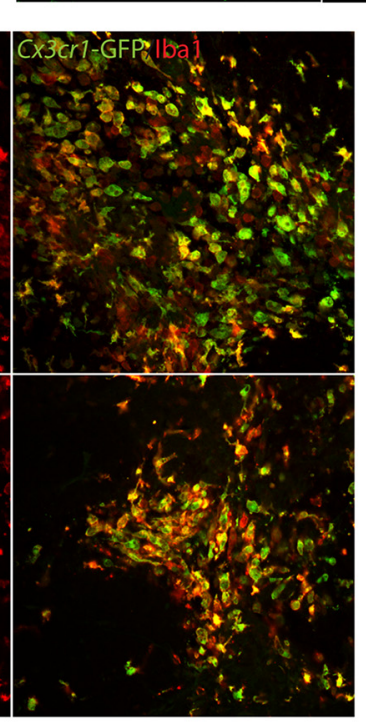

D

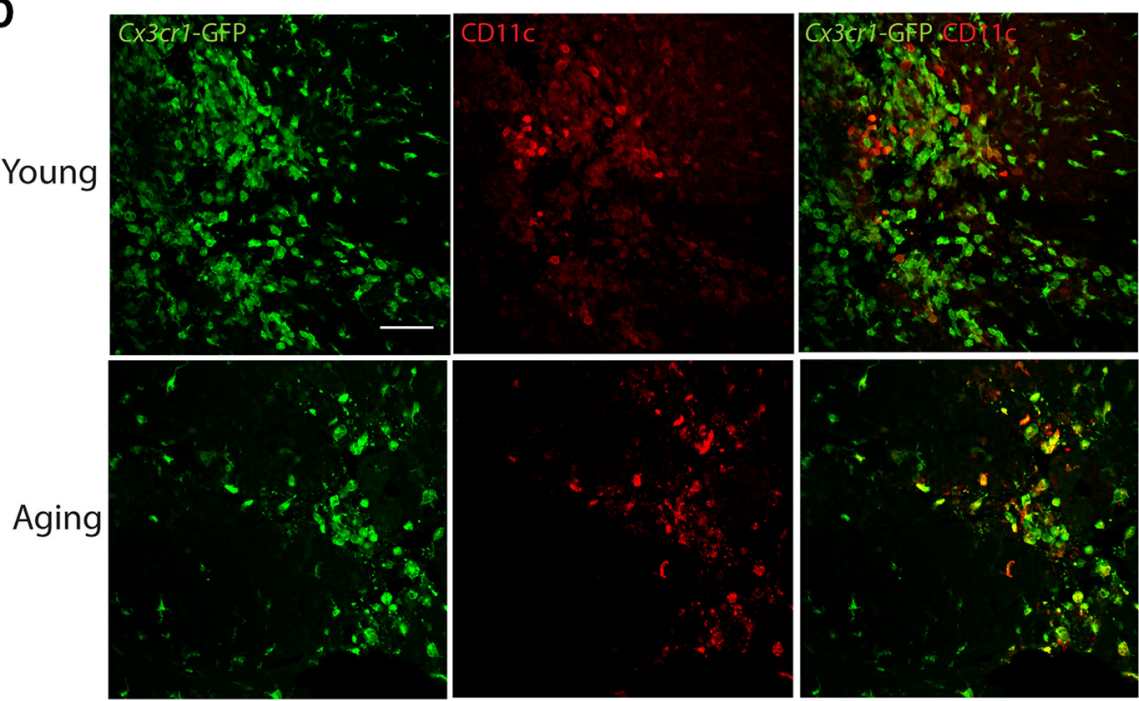

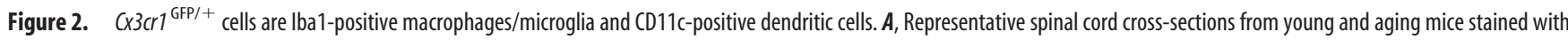
eriochrome cyanine (blue) and neutral red (red) to detect myelin and nuclei, respectively. Shown are uninjured dorsal columns and lesioned dorsal columns $3 \mathrm{~d}$ after demyelination. $B$, Representative spinal cord cross-sections of uninjured dorsal columns from young and aging mice display evenly distributed ramified $(X 3 \mathrm{cr})^{\text {GFP/+ }}$ microglia (green). Also shown are lesioned dorsal columns from young and aging mice $3 \mathrm{~d}$ after demyelination. These lesions display accumulation of $\mathrm{C} \times 3 \mathrm{cr} 1^{\mathrm{GFP} /+}$ cells. C, Representative images of demyelinated lesions from young and aging mice stained with the macrophage/microglia marker Iba1 (red). Most $\mathrm{C} \times 3 \mathrm{Cr} 1^{\mathrm{GFP} /+}$ cells (green) are also lba1-positive (orange). D, Representative images of demyelinated lesions from young and aging mice stained with CD11c (red). The majority of $\mathrm{C} \times 3 \mathrm{Cr}{ }^{1 \mathrm{GFP} /+}$ cells (green) display a low or negligible level of CD11c (orange). Also present are CD11c-positive, GFP-negative cells (red). Scale bars, $100 \mu \mathrm{m}$. 
A

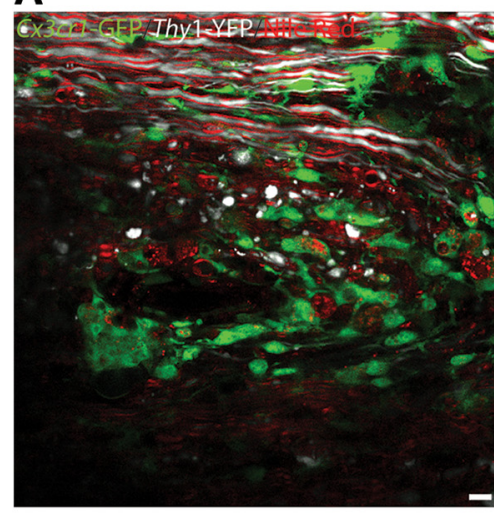

B

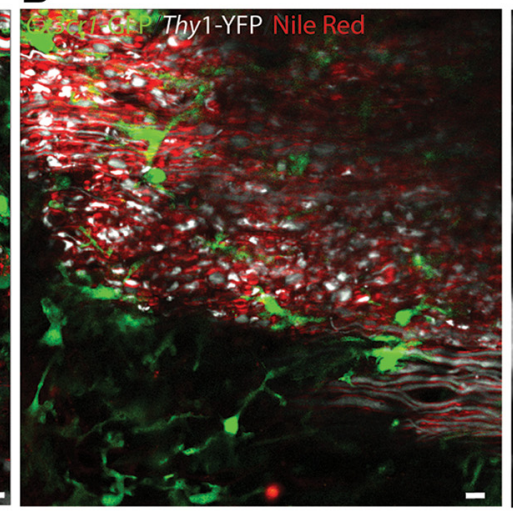

D

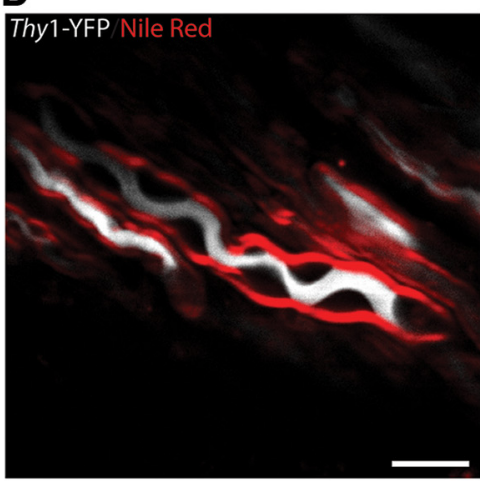

G

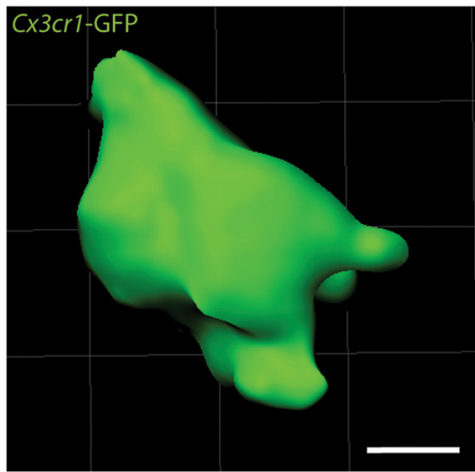

E

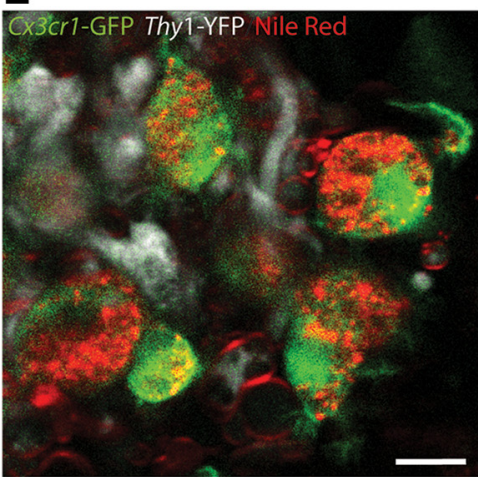

H

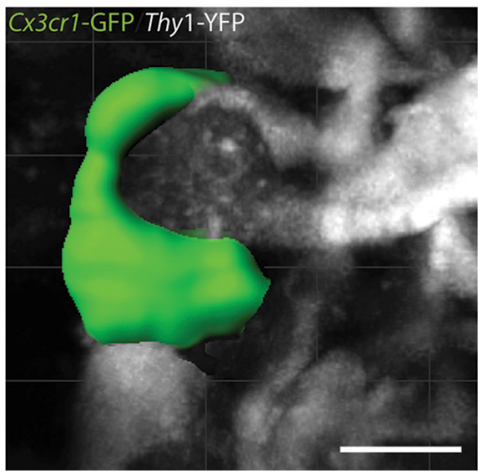

C

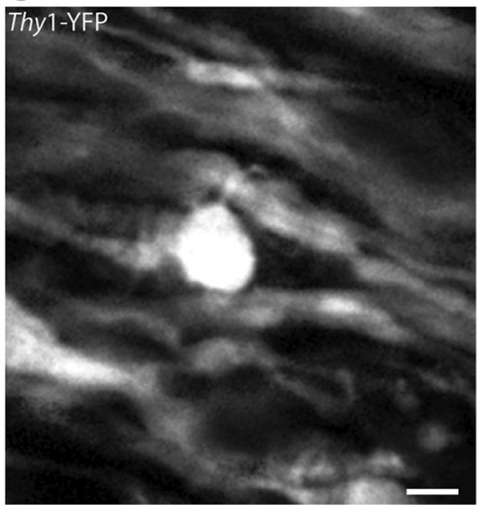

F

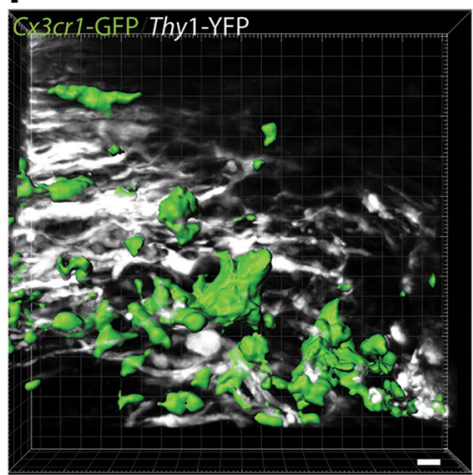

I

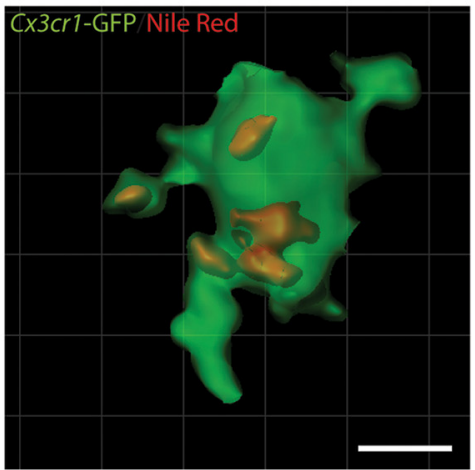

Figure 3. Ex vivo multiphoton live imaging facilitates high-resolution acquisition of many features in the lesion microenvironment. $\boldsymbol{A}$, Spectrally unmixed image depicting a demyelinated dorsal column lesion with infiltration of activated $C \times 3 \mathrm{Cr} 1^{\mathrm{GFP} /+}$ microglia and other myeloid cells (green). Nile red-positive myelin debris (red) is present within the lesion. Thy 7 YFP ${ }^{+}$axons (white) appear with axonal endbulbs. Normal appearing white matter is visible in the top portion of the image with intact Thy $7 \mathrm{YFP}^{+}$axons surrounded by normal appearing Nile red-positive myelin sheaths. $\boldsymbol{B}$, Spectrally unmixed image of a region caudal to the lesion site depicting Wallerian degeneration. This site has many Thy 7YFP ${ }^{+}$axonal endbulbs (white) and $C \times 3 \mathrm{Cr} 1^{\mathrm{GFP} /+}$ cells (green). $\boldsymbol{C}$, Denuded

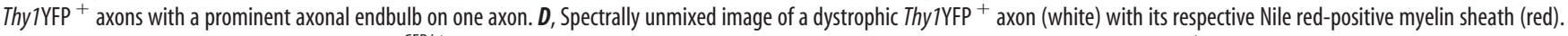
$E$, Spectrally unmixed image of phagocytic $\mathrm{XX3Cr}^{\text {GFP/+ }}$ cells (green) containing Nile red-positive phagosomes (red) within the cytoplasm. Thy $7 \mathrm{YFP}^{+}$axonal fragments (white) are also evident in

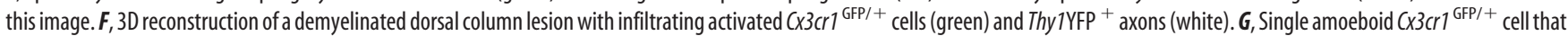
has been 3D reconstructed. $\boldsymbol{H}$, Example of a 3D-reconstructed $\mathrm{C} \times 3 \mathrm{Cr} 1^{\mathrm{GFP} /+}$ cell in the process of engulfing a Thy 7 YFP ${ }^{+}$axonal endbulb. I, 3D reconstruction of a single phagocytic $\mathrm{C} \times 3 \mathrm{Cr} 1^{\mathrm{GFP} /+}$ cell containing numerous Nile red-positive phagosomes (red) within its cytoplasm. Scale bars, $10 \mu \mathrm{m}$.

of pathological features such as axonal spheroids or myelin unraveling.

The lesioned spinal cord $3 \mathrm{~d}$ after demyelination was characterized by a focal region of denuded axons that were no longer running longitudinally (Fig. 1C). We also observed areas of Nile red-positive myelin debris, axonal spheroids, and an increase in the quantity of $C \times 3 \mathrm{cr} 1^{\mathrm{GFP} /+}$ cells in the lesion. The $C \times 3 \mathrm{cr} 1^{\mathrm{GFP} /+}$ cells appeared amoeboid in morphology and had enlarged cytoplasms, representing activated microglia and infiltrating myeloid cells. It is not possible to differentiate $\mathrm{Cx} 3 \mathrm{cr} 1$-expressing macro- phages, dendritic cells, and microglia definitively, so these are collectively referred herein as myeloid cells.

To obtain histological confirmation of demyelination using this method, we killed mice for histology and stained cyrosections with the myelin stain eriochrome cyanine. In uninjured spinal cords, the intact dorsal column appeared blue when stained with eriochrome cyanine (Fig. 2A). Within the demyelinated dorsal columns, however, a lack of blue corresponding to myelin loss was evident. These results, therefore, provide histological evidence of demyelination using this method. Furthermore, we 


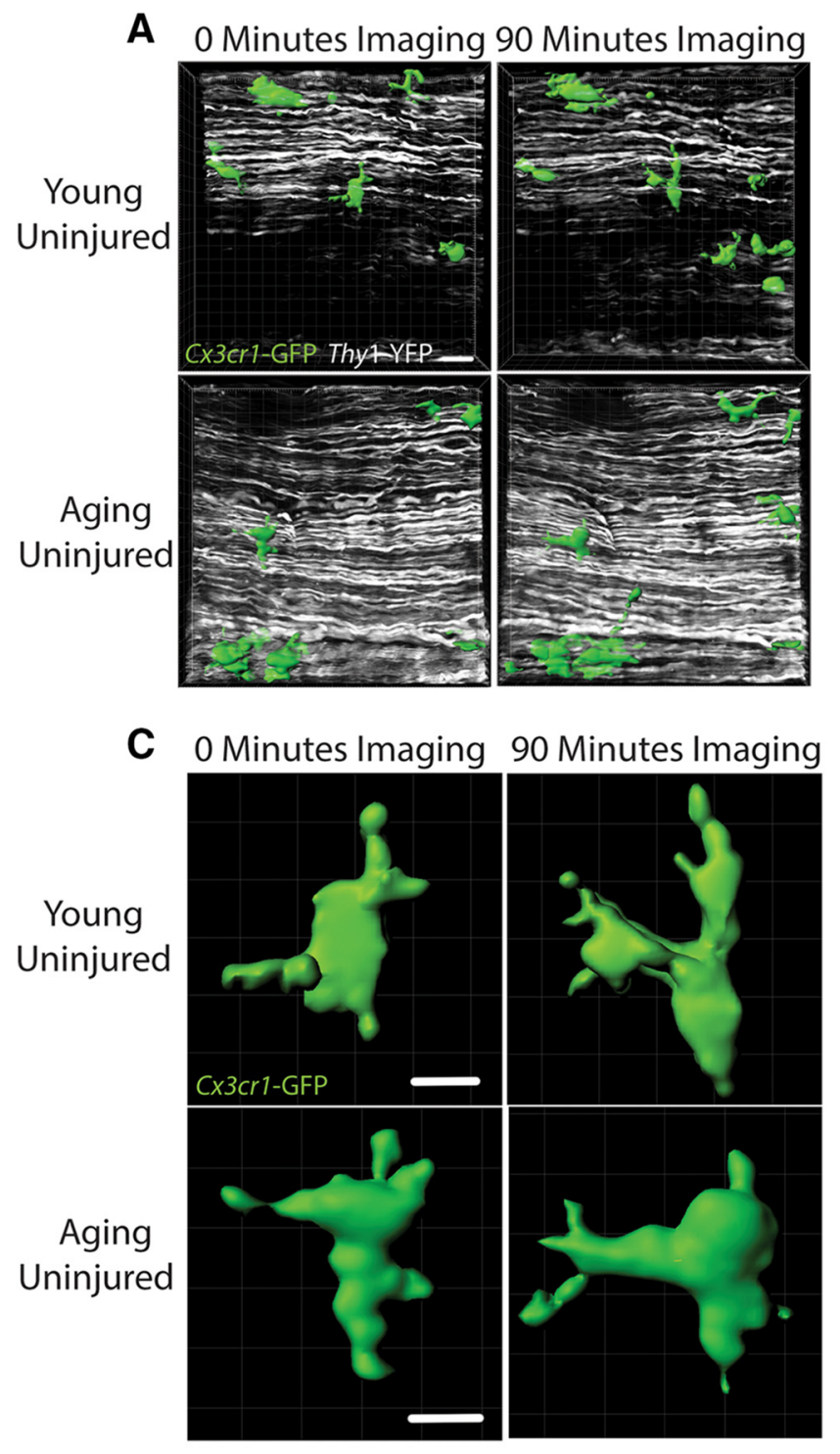

$\mathbf{E}$

\section{Cell Volume}

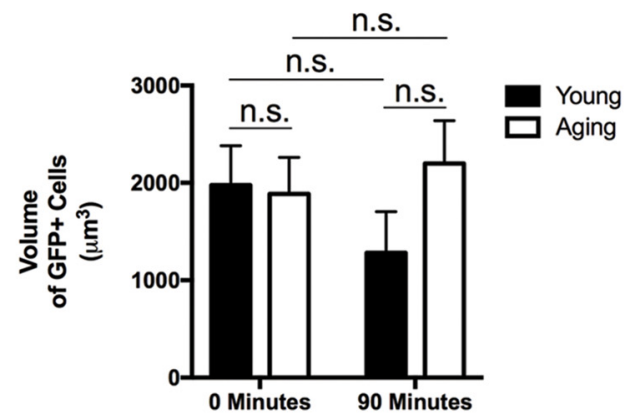

B

$$
\text { Number of Cells }
$$

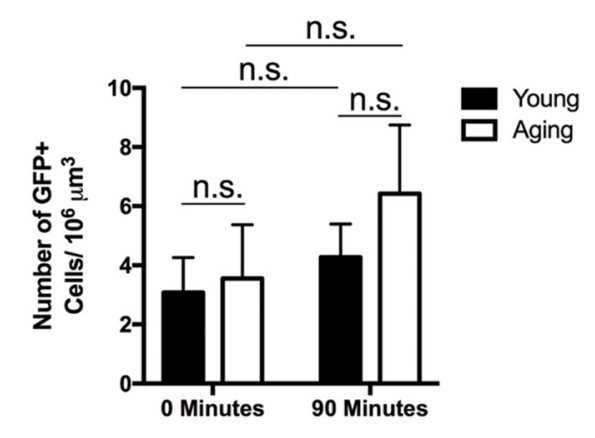

D

\section{Cell Surface Area}

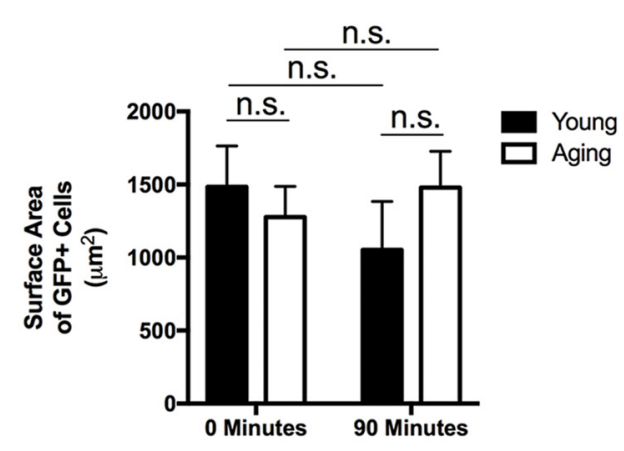

$\mathbf{F}$

Cell Sphericity

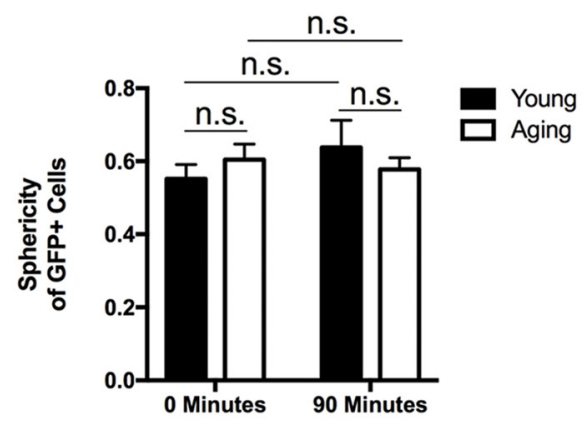

Figure 4. Live imaging of unlesioned young and aging dorsal columns does not alter microglia cell number of morphology over 90 min of imaging. $A$, Representative 3D-reconstructed still frames of time-lapse videos of uninjured dorsal columns from young and aging mice. The first time point ( 0 Minutes Imaging) and the final time point ( 90 Minutes Imaging) are displayed. CX3cr ${ }^{\mathrm{GFP} /+}$ microglia are depicted in green and Thy $7 \mathrm{YFP}^{+}$axons are shown in white. $B$, There is no change in the number of $C \times 3 \mathrm{cr} \mathrm{F}^{\mathrm{GFP} /+}$ microglia over 90 min of live imaging (interaction, $F_{(1,8)}=0.2456, p=$ 0.6335 ; time, $F_{(1,8)}=1.447, p=0.2634$; age, $\left.F_{(1,8)}=0.6102, p=0.4572\right)$. C, Representative 3 D reconstructions of a single $C \times 3 c r 1^{\text {GFP/+ }}$ microglial cell (green) from uninjured dorsal columns from young and aging mice. The same cell is shown at the first time point ( 0 Minutes Imaging) and the final time point ( 90 Minutes Imaging) for both the young and aging condition. $D$, Graph comparing the surface area of $C \times 3 \mathrm{cr} 7^{\mathrm{GPP} /+}$ microglia over the 90 min imaging session in uninjured young and aging dorsal columns (interaction, $F_{(1,62)}=1.154, p=0.2869 ;$ time, $F_{(1,62)}=0.1541, p=0.6960$; age, $\left.F_{(1,62)}=0.139, p=0.7106\right)$. $E$, Measurements of the cellular volume of $\left(x 3 \mathrm{Cr} 7^{\mathrm{GPP} /+}\right.$ microglia over the 90 min imaging session in uninjured young and aging dorsal columns (interaction, $F_{(1,62)}=1.238, p=0.2702$; time, $F_{(1,62)}=0.1773, p=0.6751 ;$ age, $\left.F_{(1,62)}=0.8302, p=0.3657\right)$. $F$, Graph depicting the mean sphericity of $C \times 3 c r 1^{\text {GFP } /+}$ microglia over the 90 min imaging session in uninjured young and aging dorsal columns (interaction, $F_{(1,62)}=1.123, p=0.2934 ;$ time, $F_{(1,62)}=0.3178, p=0.5750 ;$ age, $F_{(1,62)}=0.004751, p=0.9453$ ). Values are represented as mean and SEM. Results were analyzed with a two-way ANOVA with a Bonferroni's multiple-comparisons test. For $B$, each data point was of individual mice and 3 young mice and 3 aging mice were analyzed. For $\boldsymbol{D}-\boldsymbol{F}$, between 1 and 11 cells were quantified per mouse from 3 young mice and 3 aging mice. n.s., Not significant. Scale bars: $A, 20 \mu \mathrm{m} ; \boldsymbol{C}, 10 \mu \mathrm{m}$. 
observed evenly distributed ramified $C \times 3 c r 1^{\mathrm{GFP} /+}$ microglia in the intact dorsal column and accumulation of $\mathrm{C} \times 3 \mathrm{cr} 1^{\mathrm{GFP} /+}$ cells in the demyelinated dorsal column lesions (Fig. $2 B$ ).

We further characterized the histological sections to determine whether the $C \times 3 c r 1^{\mathrm{GFP} /+}$ cells are microglia as well as infiltrating macrophages and Cx3cr1-expressing dendritic cells, which have been described to also infiltrate the injured CNS (D'Agostino et al., 2012). We first investigated whether the C $\times 3$ cr $1^{\mathrm{GFP} /+}$ cells express the macrophage/microglia marker Iba1. Indeed, the majority of $C \times 3 c r 1^{\mathrm{GFP} /+}$ cells were Iba1 immunoreactive (Fig. 2C). To gain a better appreciation of the cellular identity of the $\mathrm{C} \times 3 \mathrm{cr} 1^{\mathrm{GFP} /+}$ cells, we stained sections for CD11c, a marker highly upregulated in dendritic cells. Many of the C $x 3 \mathrm{cr} 1^{\mathrm{GFP} /+}$ cells also displayed low expression of CD11c (Fig. $2 D)$. Because most of the $C \times 3 \mathrm{cr} 1^{\mathrm{GFP} /+}$ cells are Iba1-positive, these cells are presumably macrophages/microglia that have been reported to also upregulate CD11c after injury (Wlodarczyk et al., 2014). We also observed, however, few cells that showed high expression of CD11c and low expression of GFP, which may have been infiltrating dendritic cells. Based on this histological characterization, we were therefore likely visualizing $C \times 3 \mathrm{cr} 1^{\mathrm{GFP} /+}$ microglia, macrophages, and dendritic cells (which we refer to collectively as myeloid cells) during our live imaging experiments.

We sought to further characterize this technique and the lesion microenvironment by capturing high-resolution images of different features found within the lesion. As mentioned above, the lesion displayed an accumulation of activated myeloid cells, many of which were round and amoeboid (Fig. 3A). When imaging sites caudal to the lesion, we observed Wallerian degeneration, as depicted by the presence of axonal endbulbs and amoeboid myeloid cells (Fig. 3B). Furthermore, we documented the presence of several axonal spheroids, which is a hallmark feature of early axonal injury (Nikić et al., 2011) (Fig. 3C). Other pathological features included the appearance of dystrophic axons, in which the myelin sheath was not contiguously apposed to the axon (Fig. 3D). Finally, we observed several myeloid cells that contained Nile red-positive phagosomes, suggesting that these cells have phagocytically engulfed lipid debris (Fig. 3E)

In addition to features visualized in $2 \mathrm{D}$, surface rendering enabled the observation of several other aspects within the lesion microenvironment. Such information includes the 3D interrelation of axons and myeloid cells (Fig. 3F), morphological features of individual myeloid cells (Fig. $3 G$ ), instances of active myeloid cell phagocytosis of axonal endbulbs (Fig. $3 H$ ), and engulfed lipids within myeloid cell phagosomes (Fig. 3I). It is important to note that these features, in addition to the $2 \mathrm{D}$ aspects, were observed in lesions of both young and aging mice. Altogether, these experiments highlighted the ability to acquire high-resolution features of live healthy and lesioned spinal cord ex vivo.

Ex vivo multiphoton live imaging does not alter microglia cell number or morphology in the uninjured young and aging dorsal column

Before investigating whether lesional myeloid cells of young and aging mice display differences in their phagocytic and dynamic properties, we first sought to characterize whether the ex vivo live imaging setup induced any changes in the resting microglia population. To investigate this, we imaged three uninjured young spinal cords and three uninjured aging spinal cords for 90 min and examined whether the dissection or live imaging induced any changes in microglia cell number or morphology. As shown in Figure 4, $A$ and $B$, microglia density did not change over the 90 min of imaging, showing that the laser did no induce a response

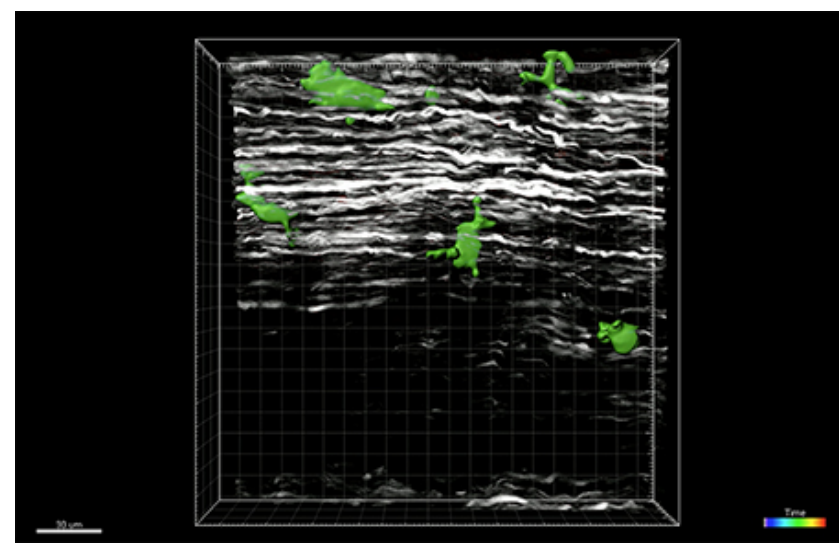

Movie 1. Although movement of processes are evident, young microglia do not migrate over 90 min of ex vivo multiphoton live imaging in the uninjured spinal cord. Shown is a 3D-reconstructed movie of a representative uninjured dorsal column from a young mouse in which every frame represents 15 min of imaging. $C \times 3 \mathrm{Cr} 1^{\mathrm{GFP} /+}$ microglia are shown in green and Thy $1 \mathrm{YFP}^{+}$axons are shown in white.
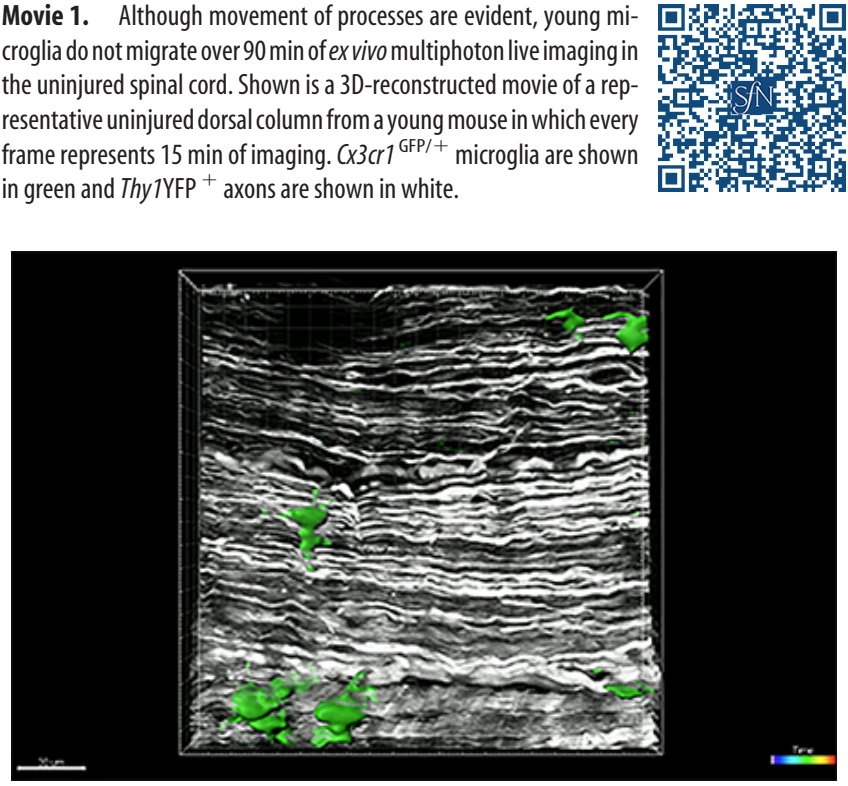

Movie 2. Aging microglia do not migrate over 90 min of ex vivo multiphoton live imaging in the uninjured spinal cord. Shown is a 3Dreconstructed movie of a representative uninjured dorsal column from an aging mouse in which every frame represents $15 \mathrm{~min}$ of imaging. $\mathrm{C} \times 3 \mathrm{Cr}^{\mathrm{GFP} /+}$ microglia are shown in green and Thy $7 \mathrm{YFP}^{+}$axons are shown in white.

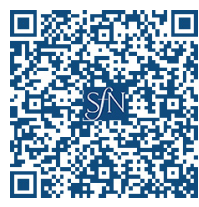

in which microglia would accumulate. To determine whether live imaging stimulated changes in morphology, we used surface rendering to measure the surface area, volume, and sphericity of individual microglial cells at each time point (Fig. 4C). We found that there was no change in these indices over the $90 \mathrm{~min}$ of imaging (Fig. 4D-F, Movie 1, Movie 2). These results demonstrate that the ex vivo live imaging setup does not promote any significant changes in microglia over the imaging session and does not induce any artifactual differences between young and aging resting microglia.

Lesions from aging mice have fewer phagocytic microglia and infiltrating myeloid cells

We next quantified the number of $\mathrm{C} x 3 \mathrm{cr} 1^{\mathrm{GFP} /+}$ myeloid cells that contained Nile red-positive phagosomes in addition to the amount of Nile red-labeled lipids engulfed by these cells. To accomplish this, we used two strategies. First, we used maximumintensity projections of spectrally unmixed images to quantify the number and percentage of $C \times 3 \mathrm{cr} 1^{\mathrm{GFP} /+}$ cells that contained Nile red-positive phagosomes within their cytoplasm. This was a $2 \mathrm{D}$ 
A True Color
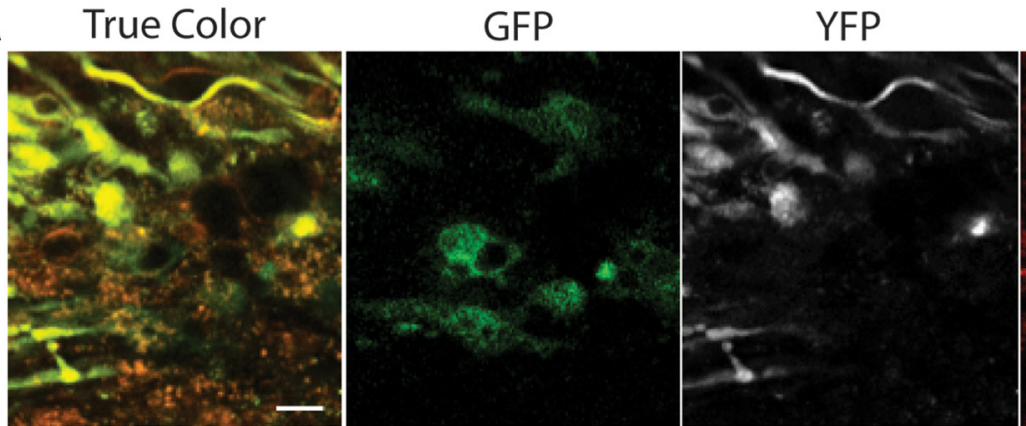

Aging
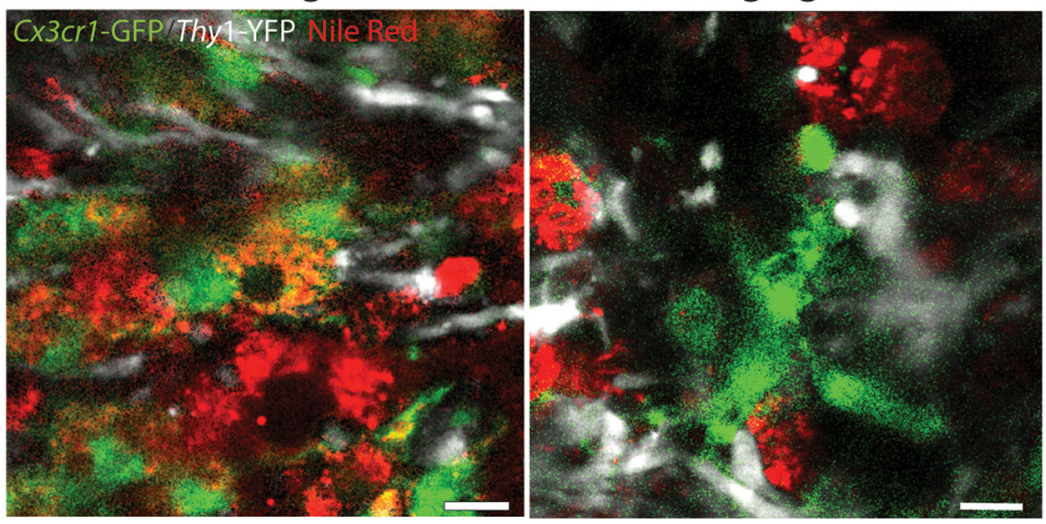

D
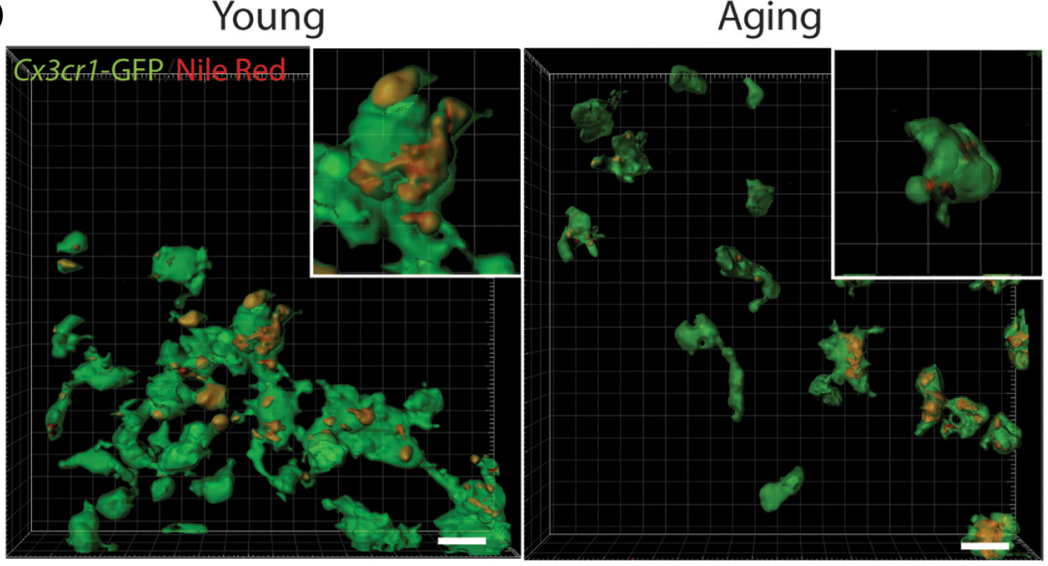

Nile Red

Spectrally Unmixed

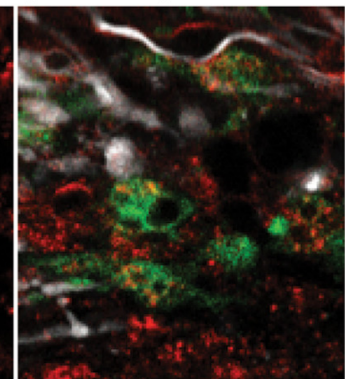

C

Number of Phagocytic Cells

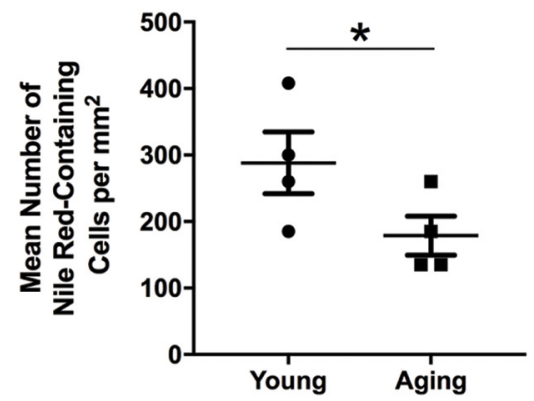

E

Percentage of Phagocytic Cells

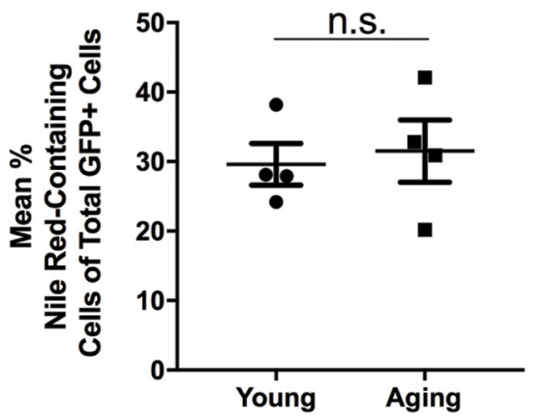

$\mathbf{F}$

Percent Phagocytosis of Total GFP

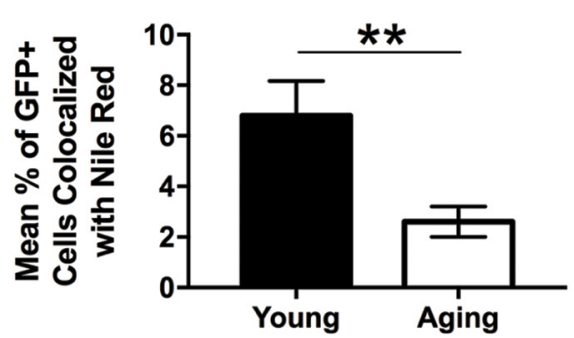

G Phagocytosed Nile Red Per GFP+ Cell

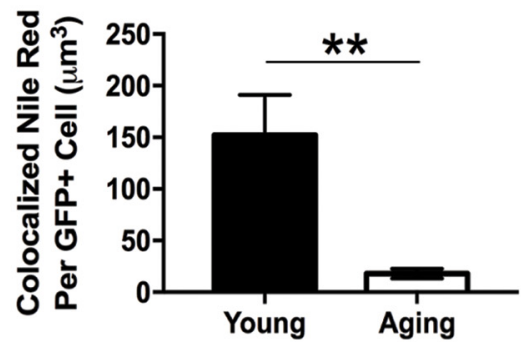

Figure 5. Lesions from aging mice have fewer Nile red-positive $C \times 3 \mathrm{Cr} 1^{\mathrm{GFP} /+}$ cells that are also less phagocytic. $A$, Example of spectral unmixing in which a true color image depicting spectral data from $490-650 \mathrm{~nm}$ is unmixed into a GFP, YFP, and Nile red channel. $\boldsymbol{B}$, Representative spectrally unmixed images from lesions in a young mouse (left) and aging mouse (right) $3 \mathrm{~d}$ after demyelination. Thy $7 \mathrm{YFP}^{+}$axons are displayed in white, Nile red-labeled myelin is shown in red, and $\mathrm{CX} 3 \mathrm{Cr} 1^{\mathrm{GFP} /+}$ cells are shown in green. $\boldsymbol{C}$, Lesions from young mice have significantly more $C \times 3 \mathrm{Cr} 1^{\text {GFP/+ }}$ cells containing Nile red-positive phagosomes than lesions from aging mice $(t=1.988, \mathrm{df}=6, p=0.0470)$. D, 3D reconstruction of $\left(x 3 \mathrm{cr} 1^{\mathrm{GFP} /+}\right.$ cells containing Nile red-positive phagosomes in lesions from young and aging mice $3 \mathrm{~d}$ after demyelination. $\boldsymbol{E}$, There is no difference in the percentage of $C \times 3 \mathrm{cr} 1^{\mathrm{GFP} /+}$ cells that contain (Figure legend continues.) 


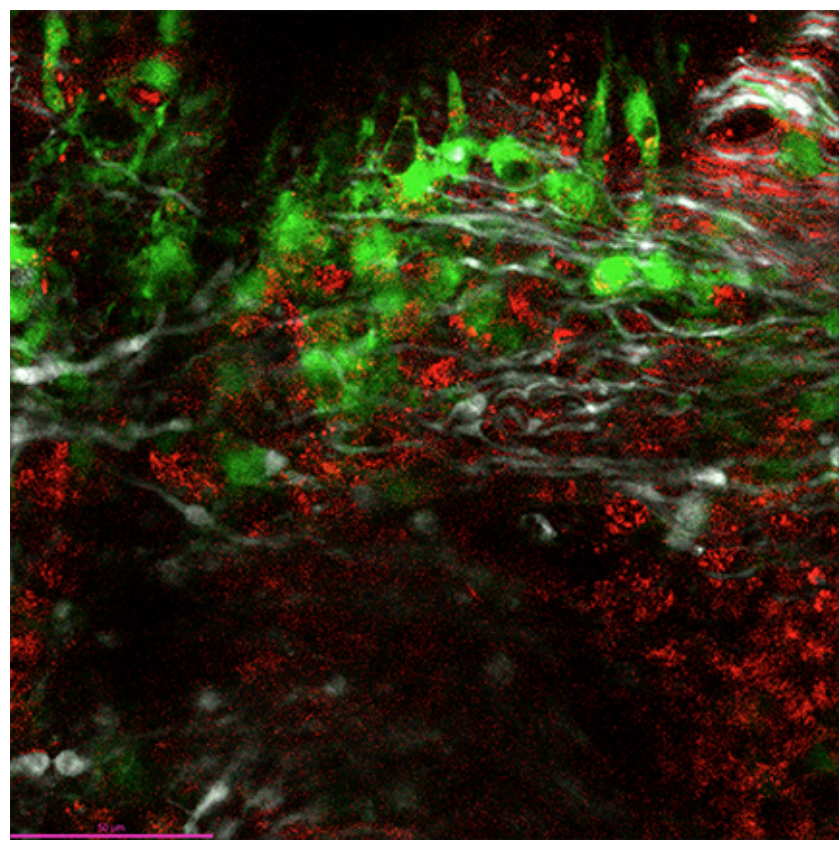

Movie 3. Lesions from young mice have a large accumulation of $\mathrm{C} \times 3 \mathrm{Cr} 1^{\mathrm{GFP} /+}$ cells that are also phagocytic. Shown is a movie depicting spectrally unmixed maximum intensity projections of a representative lesion from a young mouse in which every frame represents $15 \mathrm{~min}$ of imaging. $\mathrm{CX}_{\mathrm{Cr}} \mathrm{T}^{\mathrm{GP} /+}$ cells are shown in green, Thy $\mathrm{YFP}^{+}$axons are shown in white, and Nile red-labeled myelin is shown in red.

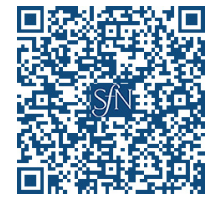

analysis and was unable to provide information regarding the amount of Nile red contained within each cell. Therefore, we used a second method in which GFP and Nile red were 3D colocalized, providing information as to how much Nile red was present within GFP-positive cells. As shown in Figure 5A, the spectral unmixing algorithm that we used is able to separate the signal discretely from the GFP, YFP, and Nile red present in one $z$ slice of the true color image. We have shown previously that this algorithm is able to distinguish spectral peaks as close as $10 \mathrm{~nm}$ apart, enabling the very close spectra of YFP and GFP to be separated (Stirling et al., 2014) and allowing $C \times 3 c r 1^{\mathrm{GFP} /+}$ cells containing Nile red to be identified easily. Using spectrally unmixed maximum intensity projections, we found that several Nile redpositive cells were present in the lesions of both young and aging mice $3 \mathrm{~d}$ after demyelination (Fig. 5B, Movie 3, Movie 4). We quantified both the number of Nile red-containing $C \times 3 \mathrm{cr} 1^{\mathrm{GFP} /+}$ cells and the percentage of $\mathrm{C} \times 3 \mathrm{cr} 1^{\mathrm{GFP} /+}$ cells with phagocytosed Nile red. Compared with young lesions, aging lesions had significantly fewer phagocytic $C \times 3 \mathrm{crl} 1^{\mathrm{GFP} /+}$ cells (Fig. $5 C$ ). There was no difference, however, in the percentage of cells that were phagocytic between young and aging lesions (Fig. 5E). Because the percentage of phagocytic cells did not differ between young

$\leftarrow$

(Figure legend continued.) Nile red-positive phagosomes in lesions from young mice compared with lesions from aging mice ( $t=0.3516, \mathrm{df}=6, p=0.3686)$. $F$, At $3 \mathrm{~d}$ after demyelination, lesions from aging mice display a significant reduction in the percentage of total GFP signal colocalized with Nile red ( $t=2.8, \mathrm{df}=54, p=0.0035)$. $\mathbf{G}$, Lesions from aging mice show a significant reduction in the amount of Nile red phagocytosed per $C \times 3 \mathrm{cr}^{6 \mathrm{GPP} /+}$ cell $(t=3.215$, $\mathrm{df}=51, p=0.0011)$. Values are represented as mean with the SEM. Results were analyzed with a one-tailed Student's $t$ test. For $\boldsymbol{C}$ and $\boldsymbol{E}$, each data point represents one mouse. For $\boldsymbol{F}$ and $G$, the percentage and volume of Nile red colocalized with $C \times 3 \mathrm{Cr}^{\mathrm{GFP} /+}$ cells, respectively, were quantified from several time points in each of 4 young mice and 4 aging mice. ${ }^{*} p<0.05 ;{ }^{* *} p<$ $0.01 ;$ n.S., Not significant. Scale bars, $10 \mu \mathrm{m}$.

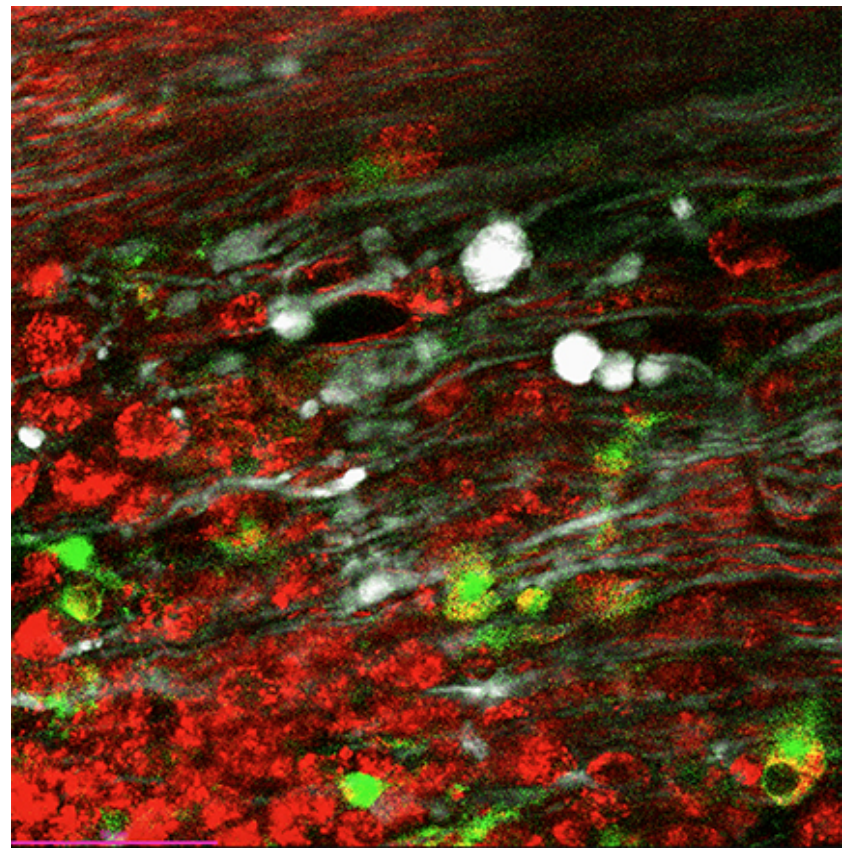

Movie 4. Lesions from aging mice do not display a large accumulation of $\mathrm{C}_{3} \mathrm{Cr}^{1}{ }^{\mathrm{GPP} /+}$ cells and do not have many phagocytic $\mathrm{C} \times 3 \mathrm{Cr}^{\mathrm{GFP} /+}$ cells. Shown is a movie depicting spectrally unmixed maximum intensity projections of a representative lesion from an aging mouse in which every frame represents 15 min of imaging. $\mathrm{CX}^{\mathrm{Cr}} \mathrm{T}^{\mathrm{GFP} /+}$ cells are shown in green, Thy $7 \mathrm{YFP}^{+}$axons are shown

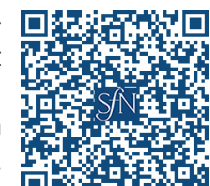
in white, and Nile red-labeled myelin is shown in red.

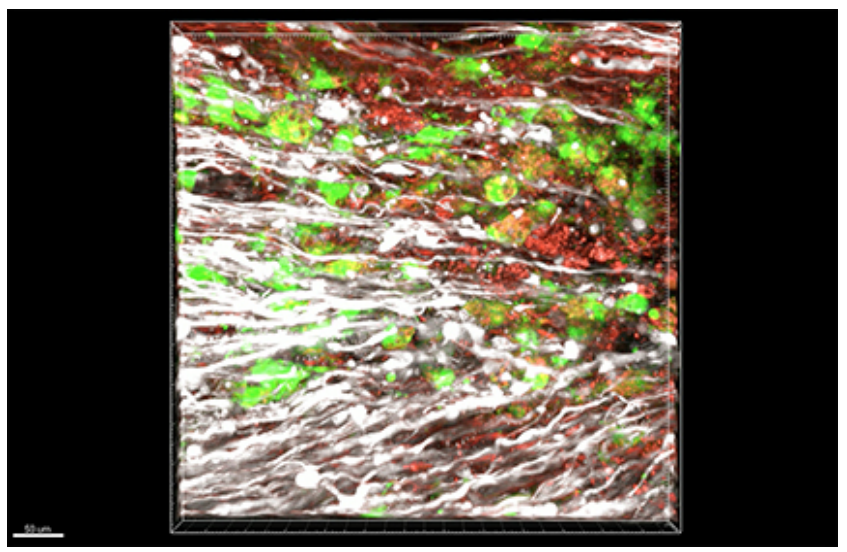

Movie 5. The young lesion microenvironment can be live imaged in $\square$ $3 \mathrm{D}$ over time with $\mathrm{CX} 3 \mathrm{Cr}^{\mathrm{GFP} /+}$ : Thy $7 \mathrm{YFP}^{+}$mice. Shown is a 3D spectrally unmixed movie of a representative lesion from a young mouse in which every frame represents 15 min of imaging. $\mathrm{CX}_{\mathrm{Cr}} \mathrm{CFP}^{\mathrm{GP} /+}$ cells are shown in green, Thy 7YFP ${ }^{+}$axons are shown in white, and Nile redlabeled myelin is shown in red. Some of the phagocytosed Nile redlabeled lipids may be obscured by the GFP signal.

and aging lesions, we questioned whether aging myeloid cells engulfed less lipid than young myeloid cells. To address this question, we used the second method in which Nile red-positive voxels were colocalized with GFP-positive voxels, thereby providing the amount of Nile red-labeled lipids engulfed by $\mathrm{C} \times 3 \mathrm{cr} 1^{\mathrm{GFP} /+}$ cells (Movie 5, Movie 6, Movie 7, Movie 8). Using this approach, we found that aging $C \times 3 \mathrm{cr} 1^{\mathrm{GFP} /+}$ cells had a significant reduction in the amount of Nile red-labeled lipids that were engulfed (Fig. $5 F, G$, Movie 7, Movie 8). It is important to note, however, that, 


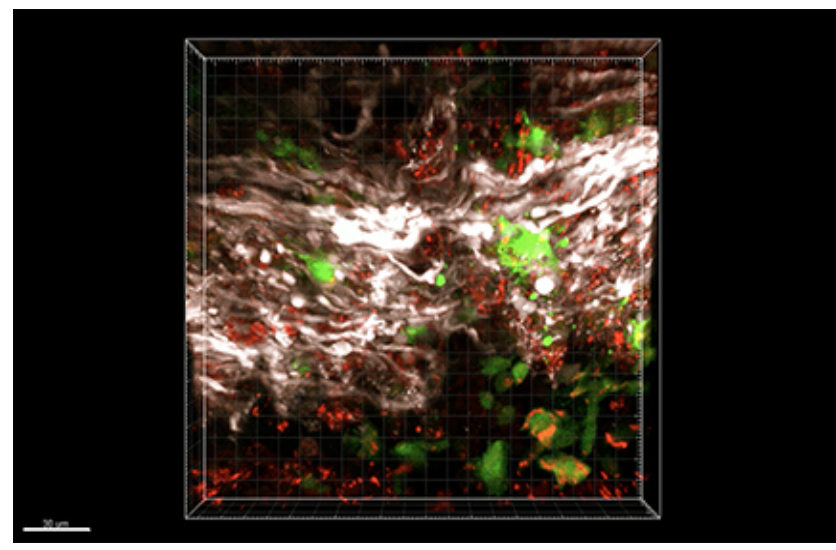

Movie 6. The aging lesion microenvironment can be live imaged in 3D over time with $\mathrm{C} \times 3 \mathrm{Cr}^{\mathrm{GFP} /+}$ : Thy $1 \mathrm{YFP}{ }^{+}$mice. Shown is a 3D spectrally unmixed movie of a representative lesion from an aging mouse in which every frame represents 15 min of imaging. $\mathrm{C} \times 3 \mathrm{Cr} 1^{\mathrm{GFP} /+}$ cells are shown in green, Thy $1 \mathrm{YFP}^{+}$axons are shown in white, and Nile redlabeled myelin is shown in red. Some of the phagocytosed Nile redlabeled lipids may be obscured by the strong GFP signal.

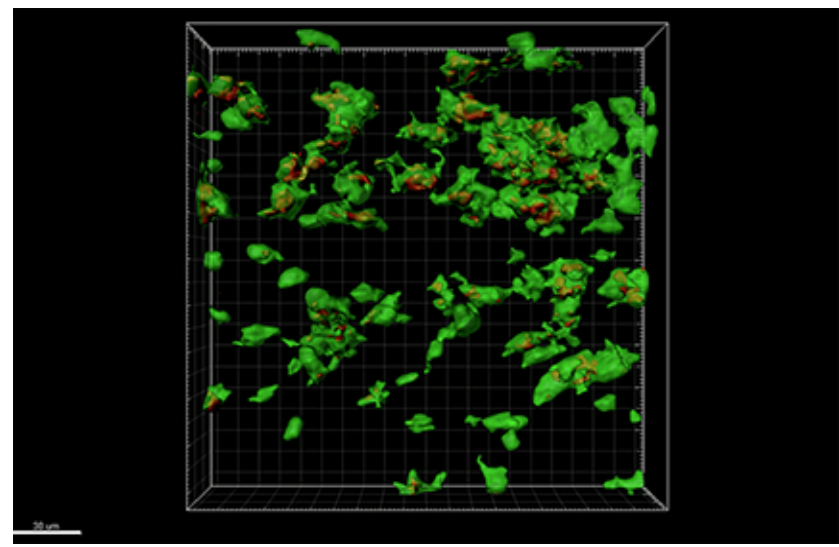

Movie 7. Lesions from young mice contain several $\mathrm{C} \times 3 \mathrm{Cr}^{\mathrm{GFP} /+}$ cells that have phagocytosed lipid debris. Shown is a 3D-reconstructed movie of a representative lesion from a young mouse in which every frame represents $15 \mathrm{~min}$ of imaging. $\mathrm{C} \times 3 \mathrm{Cr} 7^{\mathrm{GFP} /+}$ cells are shown in green. Nile red that is colocalized with GFP is shown in red and represents engulfed lipids. The GFP surfaces were made transparent to visualize engulfed lipids.

because the same anatomical location in the lesion is imaged continuously for at least $2.5 \mathrm{~h}$, there is some degree of photobleaching, which results in a decrease in both the GFP and Nile red signal over time. In summary, these results demonstrate that aging lesions have significantly fewer phagocytic myeloid cells and also display decreased engulfment of lipid debris. These deficiencies may contribute to the decreased phagocytosis of inhibitory myelin debris in aging lesions.

\section{Aging microglia and infiltrating myeloid cells have altered morphology}

Because microglia and infiltrating myeloid cells undergo a significant change in morphology after injury and features such as process extension and retraction are important for surveillance of the microenvironment, we sought to determine whether aging myeloid cells had any alterations in morphology. To address this question, we used surface rendering to measure the surface area,

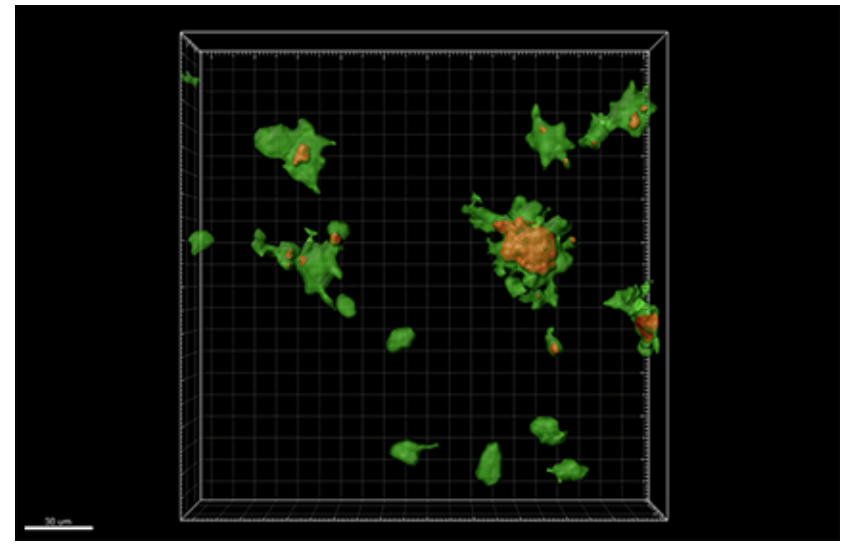

Movie 8. Lesions from aging mice display fewer $C \times 3 \mathrm{Cr}^{\mathrm{GFP} /+}$ cells $\square$ that have phagocytosed lipid debris. Shown is a 3D-reconstructed movie of a representative lesion from an aging mouse in which every frame represents $15 \mathrm{~min}$ of imaging. $\mathrm{C} \times 3 \mathrm{Cr}^{\mathrm{GFP} /+}$ cells are shown in green. Nile red that is colocalized with GFP is shown in red and represents engulfed lipids. The GFP surfaces were made transparent to visualize engulfed lipids.

volume, and sphericity of individual cells at each time point over the imaging session. We first found that both young and aging $\mathrm{C} \times 3 \mathrm{cr} 1^{\mathrm{GFP} /+}$ cells within the demyelinated lesion appeared more amoeboid compared with $C \times 3 \mathrm{cr} 1^{\mathrm{GFP} /+}$ microglia from the uninjured controls (Fig. 4C, 6A). This was accompanied by a decrease in cell surface area, volume, and an increase in sphericity. These observations highlight the change in morphology that these cells undergo from the uninjured state to the injured state. When comparing young and aging $\mathrm{C} \times 3 \mathrm{cr} 1^{\mathrm{GFP} /+}$ cells within the demyelinated lesions, aging $\mathrm{C} \times 3 \mathrm{cr} 1^{\mathrm{GFP} /+}$ cells had a significant reduction in mean surface area associated with a decrease in the number of cellular processes protruding from the cell (Fig. $6 A, B)$. In addition, aging cells displayed a significant decrease in mean cell volume (Fig. $6 C$ ). We next measured the mean sphericity of individual cells, which is defined by the ratio of the surface area of a perfect sphere to the surface area of the cell given that the sphere is volumetrically equal to the cell (Fig. 6D) (Wadell, 1935). Sphericity is therefore an indication of how amoeboid the cell is and a perfect sphere would have a sphericity of 1.0 ; any cell with protrusions would have a sphericity $<1.0$. Sphericity, however, cannot be used as an indication of the activation state of a cell. Through this measurement, we found that aging $\mathrm{C} \times 3 \mathrm{cr} 1^{\mathrm{GFP} /+}$ cells had a mean sphericity of 0.66 , whereas young cells had a mean sphericity of 0.63 (Fig. $6 D$ ), indicating that aging cells are more amoeboid and have fewer cellular protrusions with which to survey the microenvironment.

To determine whether aging cells displayed a greater degree of activation, we stained histological sections for common activation markers of myeloid cells and quantified the percentage of colocalization between $C \times 3 \mathrm{cr} 1^{\mathrm{GFP} /+}$ cells and the respective activation marker. We chose to assess $\mathrm{CD} 16 / \mathrm{CD} 32$ as well as major histocompatibility complex II (MHC II), both of which have been reported to be upregulated in proinflammatory myeloid cells (Lawrence and Natoli, 2011; Rawji and Yong, 2013). Although we found no difference in $\mathrm{CD} 16 / \mathrm{CD} 32$ between young and aging $C \times 3 \mathrm{cr} 1 \mathrm{GFP} /+$ cells, we observed a trend of increased MHC II expression in young $\mathrm{C} \times 3 \mathrm{crl}^{\mathrm{GFP} /+}$ cells (Fig. $6 E-H$ ). Because this experiment was conducted with a sample size of four to five mice, a larger sample size may establish a significant difference. In addition, because this characterization is limited to the two markers that we probed, investigat- 
A

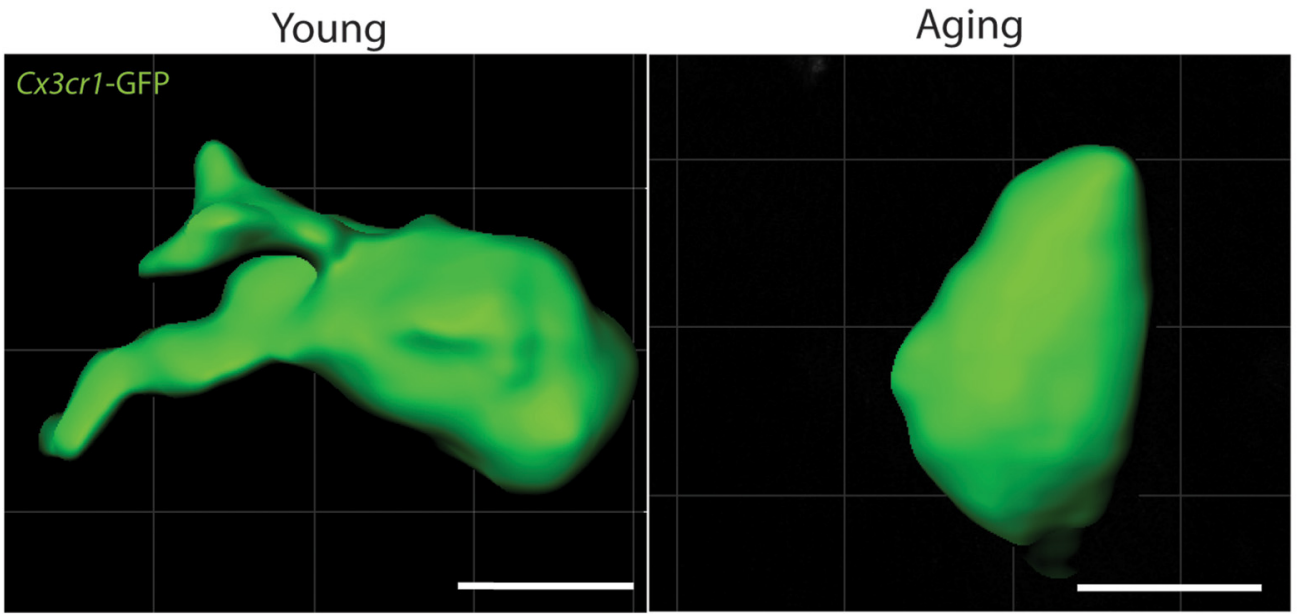

B

Mean Surface Area

C

Mean Volume

D Mean Sphericity

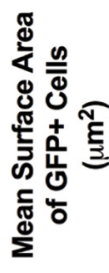

E

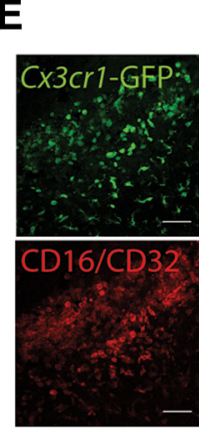

G

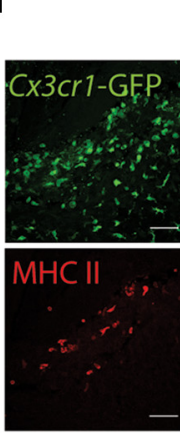

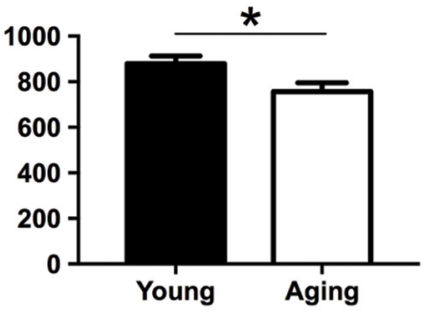

Young

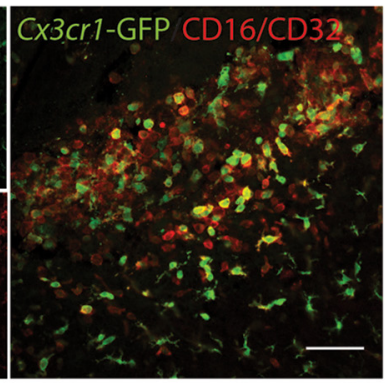

Young

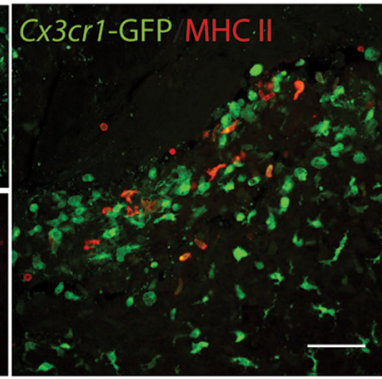

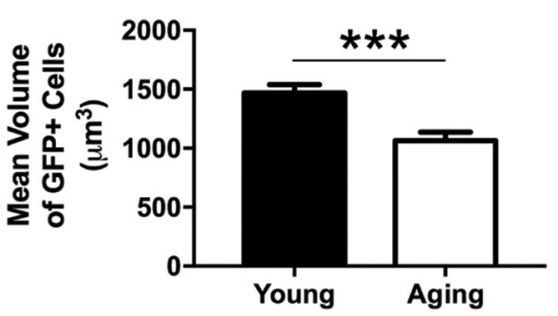

Aging

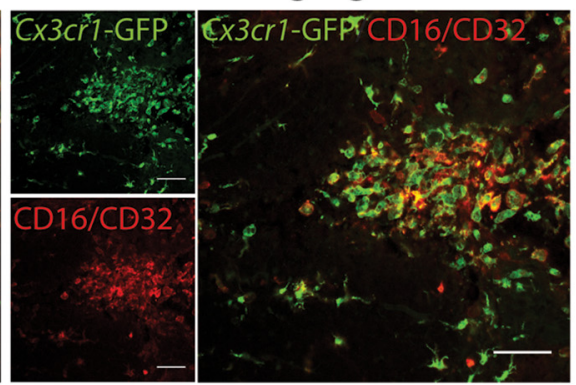

Aging

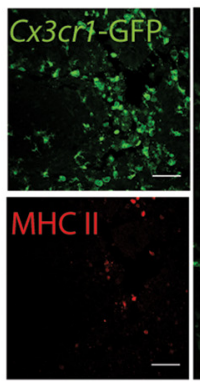

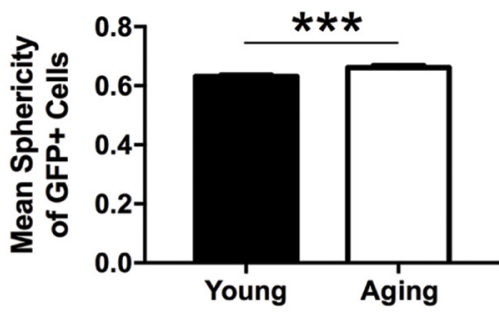

F

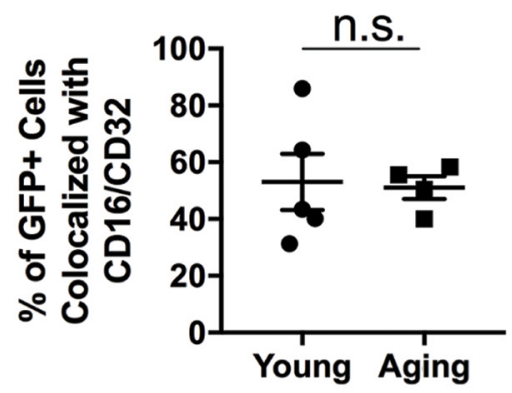

H

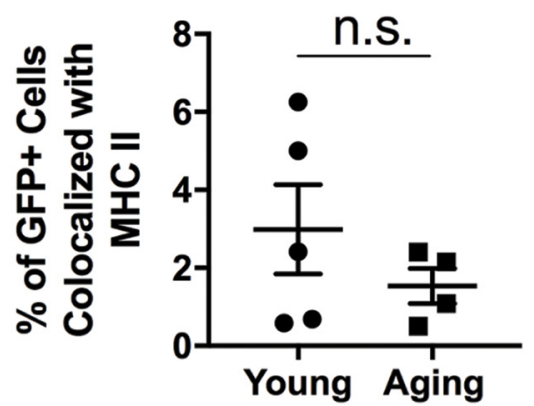

Figure 6. Lesions from aging mice have alterations in $C \times 3 \mathrm{cr} 1^{\mathrm{GFP} /+}$ cell morphology. $\boldsymbol{A}$, Representative $3 \mathrm{D}$ reconstructions of a single $C \times 3 \mathrm{cr} 1^{\mathrm{GFP} /+}$ cell from a young and an aging mouse $3 \mathrm{~d}$ after demyelination. $B$, Graph comparing the mean surface area of $C \times 3 \mathrm{Cr}^{\mathrm{GFP} /+}$ cells over the entire imaging session in lesions from young and aging mice $3 \mathrm{~d}$ after demyelination $(t=2.323, \mathrm{df}=624$, $p=0.0103)$. C, Measurements of the mean cellular volume of $C \times 3 \mathrm{cr} 1^{\mathrm{GFP} /+}$ cells over the entire imaging session in lesions from young and aging mice $3 \mathrm{~d}$ after demyelination $(t=3.768, \mathrm{df}=624$, $p<0.0001)$. D, Graph depicting the mean sphericity of $\mathrm{C} \times 3 \mathrm{Cr} 1^{\mathrm{GFP} /+}$ cells over the entire imaging session in lesions from young and aging mice $3 \mathrm{~d}$ after demyelination $(t=3.382, \mathrm{df}=624, p=$ 0.0004). $\boldsymbol{E}$, Representative images of lesions from young and aging mice immunostained with antibodies to $\left(x 3 \mathrm{cr} 1^{\mathrm{GFP} /+}\right.$ (green) and the activation marker $\mathrm{CD} 16 / \mathrm{CD} 32$ (red). Shown are the individual channels and the merged image. $\boldsymbol{F}$, There is no difference in the percentage of $C \times 3 \mathrm{cr})^{\mathrm{GFP} /+}$ cells that are colocalized with the activation marker CD16/CD32 ( $t=0.1691, \mathrm{df}=7, p=$ 0.4353). G, Representative images of lesions from young and aging mice immunostained with antibodies to $\mathrm{CX3 \textrm {Cr }}{ }^{\mathrm{GFP} /+}$ (green) and the activation marker MHC II (red). Displayed are the individual channels and the merged image. $\boldsymbol{H}$, Lesions from young mice show an increased trend in the percentage of $\left(x 3 \mathrm{cr} 1^{\mathrm{GFP} /+}\right.$ cells that are colocalized (Figure legend continues.) 


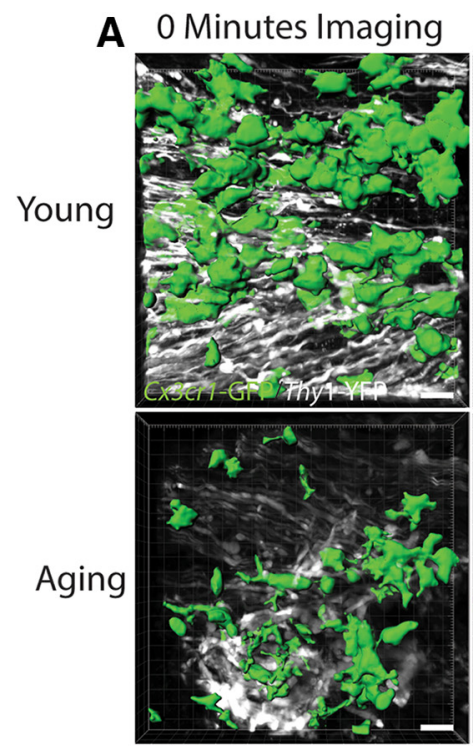

B

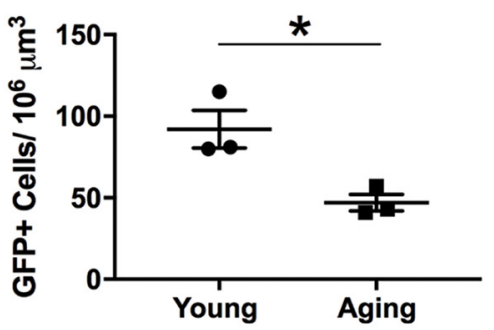

D Mean Displacement

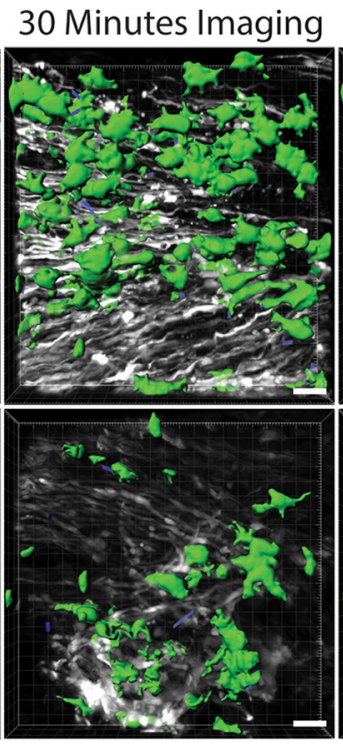

C
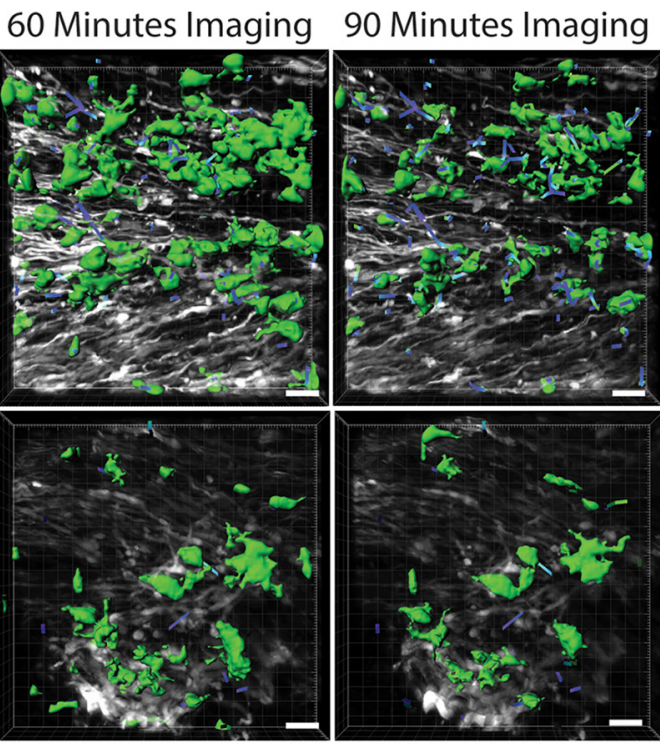

Total Displacement

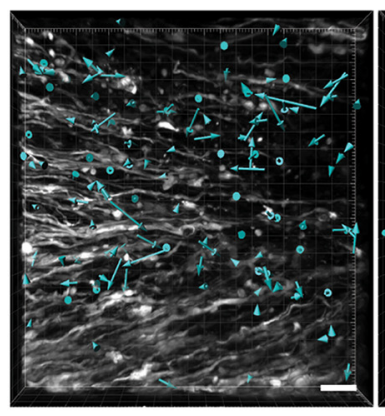

Young

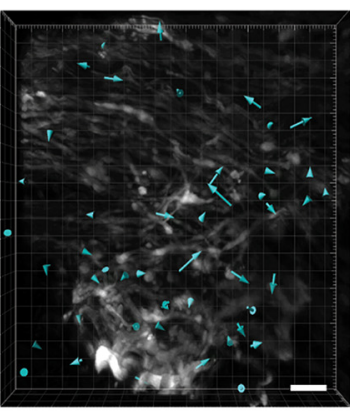

Aging

E Mean Speed

F Track Straightness
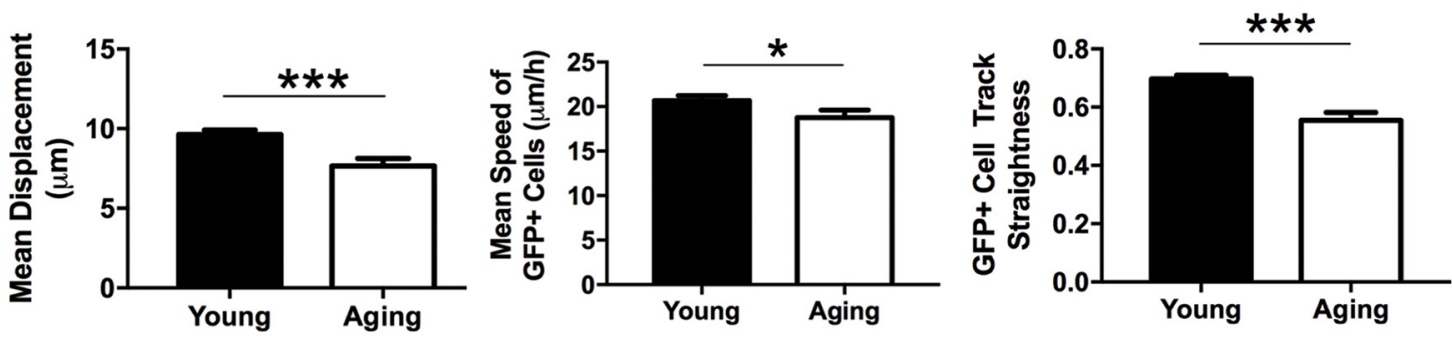

Figure 7. Aging $\left(x 3 \mathrm{Cr}^{\mathrm{GFP} /+}\right.$ cells are significantly less motile in the lesion and are fewer in number. $\boldsymbol{A}$, Representative 3D-reconstructed still frames of time-lapse videos of lesions from young and aging mice $3 \mathrm{~d}$ after demyelination. $\mathrm{CX} 3 \mathrm{cr} 1^{\mathrm{GFP} /+}$ cells are shown in green and Thy 1 YFP ${ }^{+}$axons are shown in white. Displacement vectors are shown in blue. $\boldsymbol{B}$, Lesions from young mice contain significantly more $C \times 3 \mathrm{Cr}^{\mathrm{GFP} /+}$ cells than lesions from aging mice $3 \mathrm{~d}$ after demyelination ( $t=3.584, \mathrm{df}=4, p=0.0115$ ). $C$, Representative diagram displaying displacement vectors of individual $C \times 3 \mathrm{cr})^{\mathrm{GFP} /+}$ cells over imaging session in young and aging lesions $3 \mathrm{~d}$ after demyelination. Thy $1 \mathrm{YFP}{ }^{+}$axons are shown in white. $\boldsymbol{D}, \boldsymbol{E}, \mathrm{Graphs}$ comparing the mean displacement $(t=3.631, \mathrm{df}=$ $574, p=0.0002 ; \boldsymbol{D})$ and mean speed $(t=1.778, \mathrm{df}=574, p=0.0380 ; \boldsymbol{E})$ of individual $\mathrm{C} \times 3 \mathrm{Cr} 1^{\mathrm{GFP} /+}$ cells in lesions from young and aging mice $3 \mathrm{~d}$ after demyelination. $\boldsymbol{F}, \mathrm{Graph}$ displaying the track straightness $(t=5.052, \mathrm{df}=574, p<0.0001)$ of individual $C \times 3 \mathrm{cr} 1^{\mathrm{GFP} /+}$ cells in lesions from young and aging mice $3 \mathrm{~d}$ after demyelination. Values are shown as mean and SEM. Results were analyzed with a one-tailed Student's $\boldsymbol{t}$ test. For $\boldsymbol{B}$, each data point represents one mouse. For $\boldsymbol{D}-\boldsymbol{F}$, between 41 and 145 cells were quantified per mouse from 3 young mice and 3 aging mice. ${ }^{*} p<0.05 ;{ }^{* * *} p<0.001$. Scale bars, $10 \mu \mathrm{m}$.

$\leftarrow$

(Figure legend continued.) with $\mathrm{MHC} \|(t=1.074, \mathrm{df}=7, p=0.1591)$. Values are represented as mean with the SEM. Results were analyzed with a one-tailed Student's $\boldsymbol{t}$ test. For $\boldsymbol{B}-\boldsymbol{D}$, between 41 and 145 cells were quantified per mouse from 4 young and 4 aging mice. For $F$ and $\boldsymbol{H}$, each data point represents one mouse. ${ }^{*} p<0.05 ;{ }^{* * *} p<0.001$; n.s., Not significant. For $\boldsymbol{A}$, scale bars, $10 \mu \mathrm{m}$. For $\boldsymbol{E}$ and $\boldsymbol{G}$, scale bars, $100 \mu \mathrm{m}$. ing other markers of activation or using other approaches such as transcriptomics may reveal more subtle changes in lesional myeloid cell proinflammatory activity with age.

Aging myeloid cells exhibit decreased surveillance within the demyelinated lesion

We investigated whether $\mathrm{C} x 3 \mathrm{cr} 1^{\mathrm{GFP} /+}$ cells in the lesion are dynamically active and if this activity is altered in the aging lesion. To address this question, we generated $3 \mathrm{D}$ reconstructions of the 


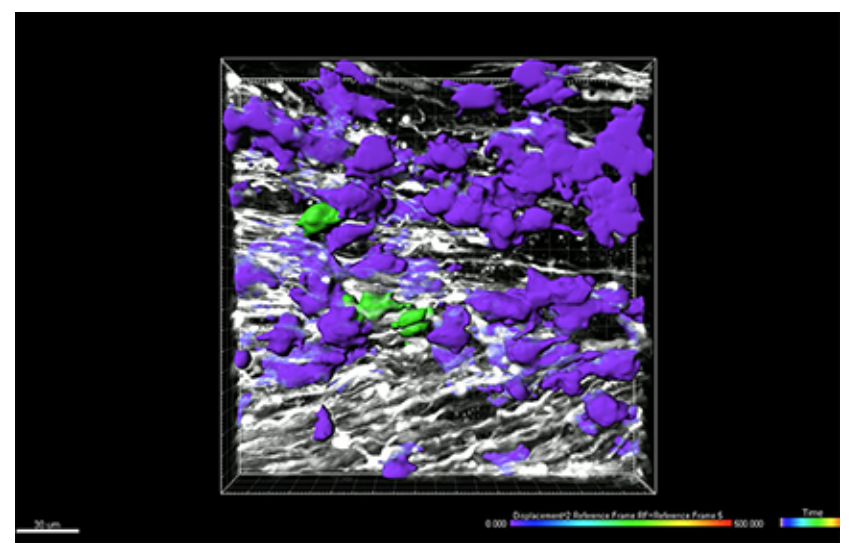

Movie 9. Young $\mathrm{C} \times 3 \mathrm{Cr}^{\mathrm{GFP} /+}$ cells are very motile in the demyelinated lesion $3 \mathrm{~d}$ after demyelination. Shown is a 3D-reconstructed movie of a representative lesion from a young mouse in which every frame represents $15 \mathrm{~min}$ of imaging. $\mathrm{C} \times 3 \mathrm{Cr} 7^{\mathrm{GFP} /+}$ cells are shown as a spectrum in which purple cells display the least displacement and red cells display the greatest displacement over $90 \mathrm{~min}$. Thy $7 \mathrm{YFP}^{+}$axons are shown in white.

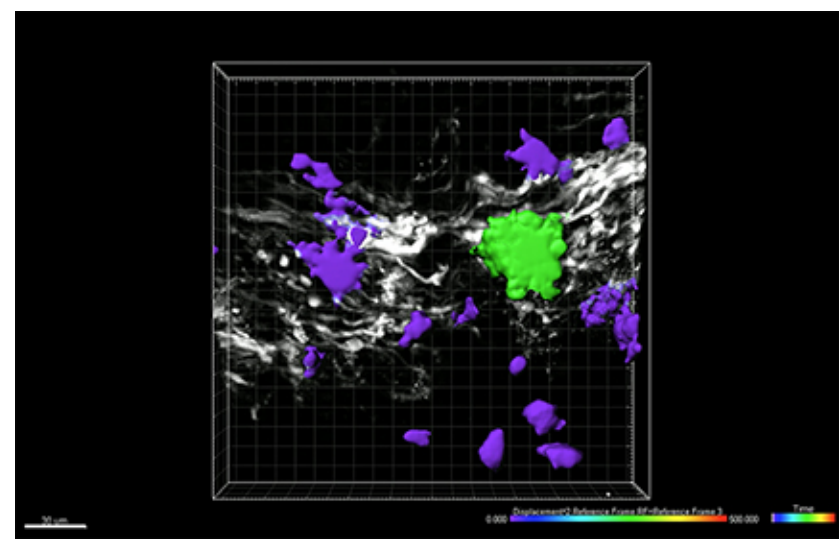

Movie 10. Aging $\mathrm{C}_{3} \mathrm{Cr}^{\mathrm{GFP} /+}$ cells do not exhibit extensive motility in the demyelinated lesion $3 \mathrm{~d}$ after demyelination. Shown is a 3D reconstructed movie of a representative lesion from an aging mouse in which every frame represents 15 min of imaging. $C \times 3 \mathrm{cr} 1^{\mathrm{GFP} /+}$ cells are shown as a spectrum in which purple cells display the least displacement and red cells display the greatest displacement over $90 \mathrm{~min}$. Thy 7 YFP ${ }^{+}$axons are shown in white.

$z$-stacks acquired at each time point over the imaging session (Fig. 7A, Movie 9, Movie 10). The 3D reconstructions enabled us to track the positions of each cell over the imaging session in the lesion. We measured the mean displacement, speed, and distance of individual $\mathrm{Cx} 3 \mathrm{cr} 1^{\mathrm{GFP} /+}$ cells over the duration of the imaging session. From these measurements, we found that $\mathrm{C} \times 3 \mathrm{cr} 1^{\mathrm{GFP} /+}$ cells are indeed motile within the lesion microenvironment (Fig. $7 A$, Movie 9, Movie 10). In addition to fewer aging $C \times 3 \mathrm{cr} 1^{\mathrm{GFP} /+}$ cells in the lesions, aging cells displayed a significant decrease in mean displacement and speed (Fig. $7 B-E$ ). These results can be further interrogated by a measurement known as the confinement index, also known as track straightness, which is defined as the ratio of the displacement to the distance (Beltman et al., 2009). Using this measurement, we found that the aging cells had a significant reduction in the track straightness, suggesting that, although aging $C \times 3 \mathrm{cr} 1^{\mathrm{GFP} /+}$ cells exhibit motility, they are more confined within the lesion volume (Fig. $7 E$ ).
Altogether, these results suggest that, in addition to less accumulation of aging myeloid cells within lesions, these cells are less phagocytic, less motile, and appear to have reduced surveillance within the lesion microenvironment.

\section{Discussion}

Ousman and David (2000) were the first to perform a detailed analysis of the recruitment of various immune cells to the lysolecithin demyelinated lesion in the adult mouse spinal cord. They found that activated macrophages/microglia were the predominant cells recruited to the lesion. Other studies have demonstrated that a depletion of macrophages results in the impairment of remyelination, not only due to a lack of myelin debris clearance, but also due to a dysregulation in important growth factors implicated in OPC maturation (Triarhou and Herndon, 1985, 1986; Kotter et al., 2001, 2005). Because these are static histological studies, it is uncertain how the macrophages/microglia were responding in real time within the demyelinated lesion. Multiphoton live imaging permits the visualization of dynamic cellular activity and this has allowed the demonstration that microglia in the healthy CNS are constantly surveying the microenvironment, retracting and extending processes in a dynamic manner (Davalos et al., 2005; Nimmerjahn et al., 2005). Furthermore, after various types of injury to the CNS, microglia quickly respond toward the lesion (Davalos et al., 2005; Nimmerjahn et al., 2005; Damani et al., 2011; Stirling et al., 2014). In a model of spinal cord injury, multiphoton time-lapse imaging demonstrated that these cells are quite migratory within the traumatic lesion cavity (Evans et al., 2014).

We used the model of ex vivo live imaging described herein for several reasons. First, as stated above, assessing static histological sections does not reveal any information on the dynamic activity of macrophages/microglia and other myeloid cells such as dendritic cells within the lesion. Understanding the dynamic properties of microglia and infiltrating myeloid cells is important in understanding their function within the lesion microenvironment. Importantly, highlighting dynamic deficiencies in the aging myeloid cell population provides more insight into how aging affects injury. Second, live imaging does not introduce the same artifacts that are introduced by fixation or freezing in traditional cryosectioning of histological sections. Such artifacts have been known to change the volume of the tissue and therefore make morphological assessments inaccurate (Chatterjee, 2014). Here, we were able to make accurate observations of morphology due to the $3 \mathrm{D}$ data acquisition in real time. Third, it is very challenging to image white matter tracts in vivo due to the deep anatomical location of these tracts in the brain. In addition, the challenges of in vivo imaging of the spinal cord arise from movement artifact introduced from the respiratory pattern and the heartbeat. Such artifacts usually require artificial ventilation and motion correction for drift introduced from the heartbeat. Although exvivo live imaging preparations do not have the substantial drift introduced from the respiratory pattern and the heartbeat, these preparations do display a degree of rotational drift that is difficult to correct. The effect of this drift is minimal, however, as our control experiments do not display any movement of the resting microglia. Nonetheless, development of more sophisticated drift correction algorithms will only enhance future ex vivo live imaging studies. Fourth, due to the delayed maturation of white matter tracts within the CNS, the use of ex vivo preparations from newborn mouse brain slices is unsuitable. Therefore, we resorted to using an ex vivo preparation of the spinal cord to examine the dynamic properties of a lesioned white 
matter tract in real time. Using this technique, we were able to keep the spinal cord morphologically viable for up to $12 \mathrm{~h}$ (Stirling et al., 2014) and to retain a ramified microglia phenotype in the uninjured context. We are able to image precisely a focal white matter lesion over time and quantify changing dynamics in myeloid cell properties. Altogether, this technique presents a novel method for investigating spinal cord white matter tracts without the challenges presented by in vivo spinal cord imaging.

For remyelination, the innate inflammatory response consisting of activated microglia and infiltrating macrophages has been shown to be essential (Kotter et al., 2001, 2005). These cells clear inhibitory myelin debris and release important growth factors for OPC recruitment and differentiation (Ruckh et al., 2012; Miron et al., 2013; Rawji et al., 2016a). This immune response, however, declines with age and is thought to contribute to the age-related decrease in remyelination efficiency (Zhao et al., 2006; Ruckh et al., 2012; Shaw et al., 2013; Natrajan et al., 2015; Rawji et al., 2016b; Safaiyan et al., 2016). Because most of these studies have been conducted in vitro or from static sections in situ, it is not known whether the dynamic activity of macrophages/microglia within the demyelinated lesion change with aging. We have therefore used high-resolution ex vivo multiphoton microscopy to image in real time the dynamic activity of microglia and other infiltrating myeloid cells such as macrophages and dendritic cells in lesions of young and aging mice that have been demyelinated with lysolecithin. We found that, at $3 \mathrm{~d}$ after demyelination, the aging lesion contained fewer total $C \times 3 \mathrm{cr} 1^{\mathrm{GFP} /+}$ cells, which may reflect a decrease in the recruitment, proliferation, or perhaps a deficiency in both of these processes. Of the less myeloid cells present in the aging lesions, significantly fewer contained phagosomes labeled with the lipophilic dye Nile red. It is important to note, however, that the percentage of phagocytic cells did not differ between young and aging lesions, suggesting that aging cells are not impaired in the engulfment of lipid debris. However, there was significantly less Nile red present within each aging cell. These results suggest that the reduced phagocytosis of inhibitory myelin debris in aging lesions is due to both a decrease in the number of aging phagocytes to the lesion and a reduction in the amount of myelin debris taken up by aging myeloid cells. Because these lesions were analyzed relatively early at $3 \mathrm{~d}$ after demyelination, the percentage of $\mathrm{C} \times 3 \mathrm{cr} 1^{\mathrm{GFP} /+}$ cells containing Nile redpositive debris was $<10 \%$. Analysis of later time points after demyelination will likely result in a greater percentage of $\mathrm{C} \times 3 \mathrm{crl} \mathrm{GFP}^{\mathrm{GF} /+}$ cells containing Nile red-positive debris.

In addition, the motility of aging $C \times 3 \mathrm{cr} 1^{\mathrm{GFP} /+}$ cells within the lesion was significantly reduced compared with young cells and many aging cells also appeared stationary. Furthermore, aging myeloid cells have fewer cellular processes than young cells, potentially contributing to a reduction in the surveillance of the surrounding microenvironment. Altogether, these results suggest that, in addition to there being fewer cells in the aging lesion, the phagocytic capacity and surveillance activity of these cells is also lowered, potentially contributing to the reduced clearance of inhibitory molecules and therefore delayed remyelination in the aging CNS.

The finding of reduced activity of aging $C \times 3 c r 1^{\mathrm{GFP} /+}$ cells within the lesion environment may reflect intrinsic deficiencies of the aging innate immune cells or extrinsic changes in the aging lesion microenvironment, such as the elevated amounts of undefined inhibitors of myeloid cell functions or changes in the stiffness of the extracellular matrix (Rawji et al., 2016b). An approach to resolving lesion-intrinsic or environmental mechanisms could be the implant of young myeloid cells into the young versus aging brain. Indeed, when aging lysolecithin-demyelinated mice were paired with young mice through heterochronic parabiosis, young macrophages were observed to infiltrate the aging lesion, resulting in enhanced myelin debris clearance and improved remyelination (Ruckh et al., 2012). Moreover, investigating the potential factors underlying the decreased activity of aging myeloid cells should reveal important targets to help enhance surveillance and repair within the aging demyelinated lesion. Further, medications to enhance the activity of myeloid cells in aging lesions may improve the phagocytic clearance of inhibitory myelin debris, thereby providing a more conducive environment for OPCs to mature into myelinating oligodendrocytes. This approach was shown to be effective in young mice, in which combined treatment with amphotericin B, which stimulates activity, and macrophage colony stimulating factor, which increases cell numbers, increased representation of macrophages/microglia in the demyelinated lesion and promoted remyelination (Döring et al., 2015).

In conclusion, we have used a high-resolution multiphoton live imaging technique to examine the dynamic activity of young and aging $\mathrm{C} \times 3 \mathrm{cr} 1^{\mathrm{GFP} /+}$ myeloid cells in the demyelinated spinal cord. We found that these cells are not static in the lesion, but are active and motile within the microenvironment. Importantly, aging cells exhibit decreased motility and phagocytosis, contributing to the lack of debris clearance in the aging CNS. Strategies that enhance the intralesional motility and phagocytic potential of aging myeloid cells may promote remyelination in the aging CNS. In addition, we have described a novel technique to examine, in high resolution, the pathophysiology of the demyelinated lesion in real time.

\section{References}

Arnaud E, Zenker J, de Preux Charles AS, Stendel C, Roos A, Médard JJ, Tricaud N, Kleine H, Luscher B, Weis J, Suter U, Senderek J, Chrast R (2009) SH3TC2/KIAA1985 protein is required for proper myelination and the integrity of the node of ranvier in the peripheral nervous system. Proc Natl Acad Sci U S A 106:17528-17533. CrossRef Medline

Beltman JB, Marée AF, de Boer RJ (2009) Analysing immune cell migration. Nat Rev Immunol 9:789-798. CrossRef Medline

Chatterjee S (2014) Artefacts in histopathology. J Oral Maxillofac Pathol 18:S111-S116. CrossRef Medline

D'Agostino PM, Gottfried-Blackmore A, Anandasabapathy N, Bulloch K (2012) Brain dendritic cells: biology and pathology. Acta Neuropathol 124:599-614. CrossRef Medline

Damani MR, Zhao L, Fontainhas AM, Amaral J, Fariss RN, Wong WT (2011) Age-related alterations in the dynamic behavior of microglia. Aging Cell 10:263-276. CrossRef Medline

Davalos D, Grutzendler J, Yang G, Kim JV, Zuo Y, Jung S, Littman DR, Dustin ML, Gan WB (2005) ATP mediates rapid microglial response to local brain injury in vivo. Nat Neurosci 8:752-758. CrossRef Medline

Döring A, Sloka S, Lau L, Mishra M, van Minnen J, Zhang X, Kinniburgh D, Rivest S, Yong VW (2015) Stimulation of monocytes, macrophages, and microglia by amphotericin B and macrophage colony-stimulating factor promotes remyelination. J Neurosci 35:1136-1148. CrossRef Medline

Evans TA, Barkauskas DS, Myers JT, Hare EG, You JQ, Ransohoff RM, Huang AY, Silver J (2014) High-resolution intravital imaging reveals that blood-derived macrophages but not resident microglia facilitate secondary axonal dieback in traumatic spinal cord injury. Exp Neurol 254:109120. CrossRef Medline

Feng G, Mellor RH, Bernstein M, Keller-Peck C, Nguyen QT, Wallace M, Nerbonne JM, Lichtman JW, Sanes JR (2000) Imaging neuronal subsets in transgenic mice expressing multiple spectral variants of GFP. Neuron 28:41-51. CrossRef Medline

Franklin RJ, Ffrench-Constant C (2008) Remyelination in the CNS: from biology to therapy. Nat Rev Neurosci 9:839-855. CrossRef Medline

Franklin RJ, Kotter MR (2008) The biology of CNS remyelination: the key to therapeutic advances. J Neurol 255:19-25. CrossRef Medline

Irvine KA, Blakemore WF (2008) Remyelination protects axons from 
demyelination-associated axon degeneration. Brain 131:1464-1477. CrossRef Medline

Jung S, Aliberti J, Graemmel P, Sunshine MJ, Kreutzberg GW, Sher A, Littman DR (2000) Analysis of fractalkine receptor CX(3)CR1 function by targeted deletion and green fluorescent protein reporter gene insertion. Mol Cell Biol 20:4106-4114. CrossRef Medline

Kotter MR, Setzu A, Sim FJ, Van Rooijen N, Franklin RJ (2001) Macrophage depletion impairs oligodendrocyte remyelination following lysolecithininduced demyelination. Glia 35:204-212. CrossRef Medline

Kotter MR, Zhao C, van Rooijen N, Franklin RJ (2005) Macrophagedepletion induced impairment of experimental CNS remyelination is associated with a reduced oligodendrocyte progenitor cell response and altered growth factor expression. Neurobiol Dis 18:166-175. CrossRef Medline

Kotter MR, Stadelmann C, Hartung HP (2011) Enhancing remyelination in disease-can we wrap it up? Brain 134:1882-1900. CrossRef Medline

Lawrence T, Natoli G (2011) Transcriptional regulation of macrophage polarization: enabling diversity with identity. Nat Rev Immunol 11:750761. CrossRef Medline

Matute C, Ransom BR (2012) Roles of white matter in central nervous system pathophysiologies. ASN Neuro 4:e00079. CrossRef Medline

Miron VE, Boyd A, Zhao JW, Yuen TJ, Ruckh JM, Shadrach JL, van Wijngaarden P, Wagers AJ, Williams A, Franklin RJ, Ffrench-Constant C (2013) M2 microglia and macrophages drive oligodendrocyte differentiation during CNS remyelination. Nat Neurosci 16:1211-1218. CrossRef Medline

Natrajan MS, de la Fuente AG, Crawford AH, Linehan E, Nuñez V, Johnson KR, Wu T, Fitzgerald DC, Ricote M, Bielekova B, Franklin RJ (2015) Retinoid X receptor activation reverses age-related deficiencies in myelin debris phagocytosis and remyelination. Brain 138:3581-3597. CrossRef Medline

Nikić I, Merkler D, Sorbara C, Brinkoetter M, Kreutzfeldt M, Bareyre FM, Brück W, Bishop D, Misgeld T, Kerschensteiner M (2011) A reversible form of axon damage in experimental autoimmune encephalomyelitis and multiple sclerosis. Nat Med 17:495-499. CrossRef Medline

Nimmerjahn A, Kirchhoff F, Helmchen F (2005) Resting microglial cells are highly dynamic surveillants of brain parenchyma in vivo. Science 308 : 1314-1318. CrossRef Medline

Ousman SS, David S (2000) Lysophosphatidylcholine induces rapid recruitment and activation of macrophages in the adult mouse spinal cord. Glia 30:92-104. CrossRef Medline

Rawji KS, Yong VW (2013) The benefits and detriments of macrophages/ microglia in models of multiple sclerosis. Clin Dev Immunol 2013: 948976. CrossRef Medline
Rawji KS, Mishra MK, Yong VW (2016a) Regenerative capacity of macrophages for remyelination. Front Cell Dev Biol 4:47. CrossRef Medline

Rawji KS, Mishra MK, Michaels NJ, Rivest S, Stys PK, Yong VW (2016b) Immunosenescence of microglia and macrophages: impact on the ageing central nervous system. Brain 139:653-661. CrossRef Medline

Ruckh JM, Zhao JW, Shadrach JL, van Wijngaarden P, Rao TN, Wagers AJ, Franklin RJ (2012) Rejuvenation of regeneration in the aging central nervous system. Cell Stem Cell 10:96-103. CrossRef Medline

Saab AS, Tzvetanova ID, Nave KA (2013) The role of myelin and oligodendrocytes in axonal energy metabolism. Curr Opin Neurobiol 23:10651072. CrossRef Medline

Saederup N, Cardona AE, Croft K, Mizutani M, Cotleur AC, Tsou CL, Ransohoff RM, Charo IF (2010) Selective chemokine receptor usage by central nervous system myeloid cells in CCR2-red fluorescent protein knock-in mice. PLoS One 5:e13693. CrossRef Medline

Safaiyan S, Kannaiyan N, Snaidero N, Brioschi S, Biber K, Yona S, Edinger AL, Jung S, Rossner MJ, Simons M (2016) Age-related myelin degradation burdens the clearance function of microglia during aging. Nat Neurosci 19:995-998. CrossRef Medline

Shaw AC, Goldstein DR, Montgomery RR (2013) Age-dependent dysregulation of innate immunity. Nat Rev Immunol 13:875-887. CrossRef Medline

Stirling DP, Cummins K, Mishra M, Teo W, Yong VW, Stys P (2014) Tolllike receptor 2-mediated alternative activation of microglia is protective after spinal cord injury. Brain 137:707-723. CrossRef Medline

Triarhou LC, Herndon RM (1985) Effect of macrophage inactivation on the neuropathology of lysolecithin-induced demyelination. Br J Exp Pathol 66:293-301. Medline

Triarhou LC, Herndon RM (1986) The effect of dexamethasone on L-alpha-lysophosphatidyl choline (lysolecithin)-induced demyelination of the rat spinal cord. Arch Neurol 43:121-125. CrossRef Medline

Wadell H (1935) Volume, shape, and roundness of quartz particles. The Journal of Geology, vol. 43, issue 3, pp. 250-280. CrossRef

Wlodarczyk A, Løbner M, Cédile O, Owens T (2014) Comparison of microglia and infiltrating $\mathrm{CD} 11 \mathrm{c}(+)$ cells as antigen presenting cells for $\mathrm{T}$ cell proliferation and cytokine response. J Neuroinflammation 11:57. CrossRef Medline

Yuen TJ, Johnson KR, Miron VE, Zhao C, Quandt J, Harrisingh MC, Swire M, Williams A, McFarland HF, Franklin RJ, Ffrench-Constant C (2013) Identification of endothelin 2 as an inflammatory factor that promotes central nervous system remyelination. Brain 136:1035-1047. CrossRef Medline

Zhao C, Li WW, Franklin RJ (2006) Differences in the early inflammatory responses to toxin-induced demyelination are associated with the agerelated decline in CNS remyelination. Neurobiol Aging 27:1298-1307. CrossRef Medline 